Analysis of Well ER-6-2 Testing, Yucca Flat FY 2004 Testing Program, Nevada Test Site, Nye County, Nevada

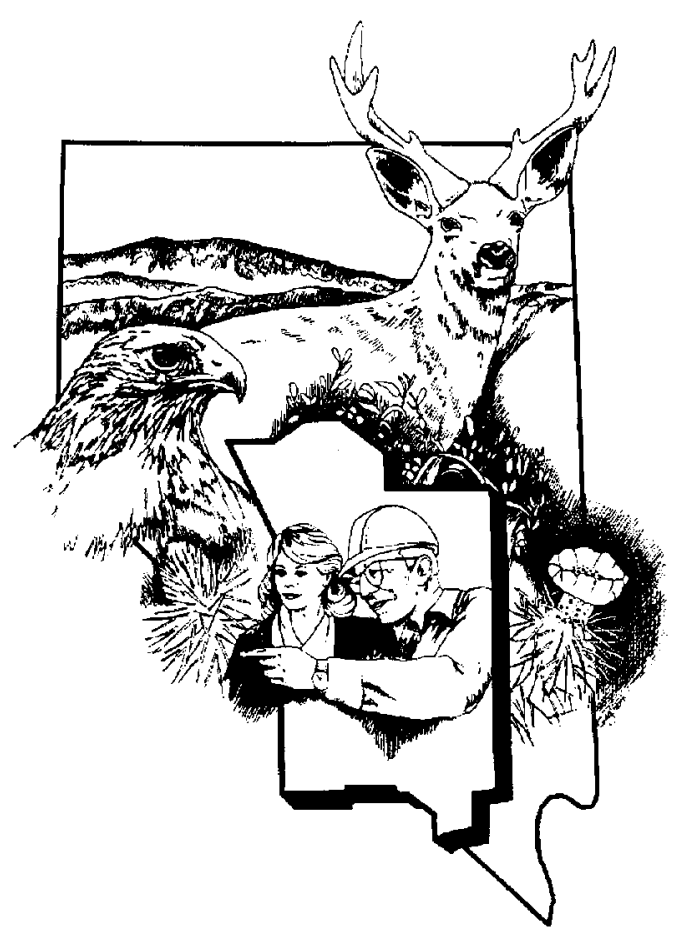

Revision No.: 0

July 2005

Prepared for U.S. Department of Energy under Contract No. DE-AC52-03NA99205

Approved for public release; further dissemination unlimited. 
Available for sale to the public from:

U.S. Department of Commerce

National Technical Information Service

5285 Port Royal Road

Springfield, VA 22161

Phone: 800.553 .6847

Fax: 703.605.6900

Email: orders@ntis.gov

Online ordering: http://www.ntis.gov/ordering.htm

Available electronically at $h t t p: / / w w w . o s t i . g o v / b r i d g e$

Available for a processing fee to U.S. Department of Energy and its contractors, in paper, from:

U.S. Department of Energy

Office of Scientific and Technical Information

P.O. Box 62

Oak Ridge, TN 37831-0062

Phone: 865.576 .8401

Fax: 865.576.5728

Email: reports@adonis.osti.gov

Reference herein to any specific commercial product, process, or service by trade name, trademark, manufacturer, or otherwise, does not necessarily constitute or imply its endorsement, recommendation, or favoring by the United States Government or any agency thereof or its contractors or subcontractors. 


\section{ANALYSIS OF WELL ER-6-2 TESTING, YUCCA FLAT FY 2004 TESTING PROGRAM, NEVADA TEST SITE, NYE COUNTY, NEVADA}

Revision No.: 0

July 2005

William Fryer, Eric Bhark

Stoller-Navarro Joint Venture

7710 W. Cheyenne, Building 3

Las Vegas, NV 89129 
ANALYSIS OF WELL ER-6-2 TESTING, YUCCA FLAT FY 2004 TESTING PROGRAM, NEVADA TEST SITE, NYE COUNTY, NEVADA 


\section{Table of Contents}

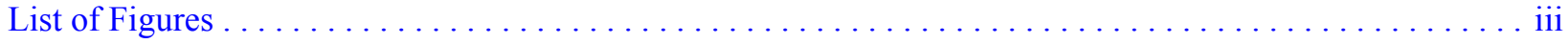

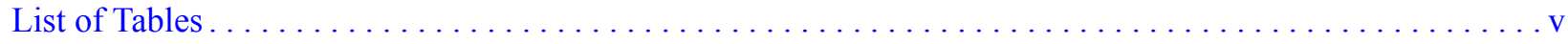

List of Acronyms and Abbreviations $\ldots \ldots \ldots \ldots \ldots \ldots \ldots \ldots \ldots \ldots \ldots \ldots \ldots \ldots \ldots \ldots \ldots \ldots \ldots \ldots \ldots \ldots \ldots \ldots$

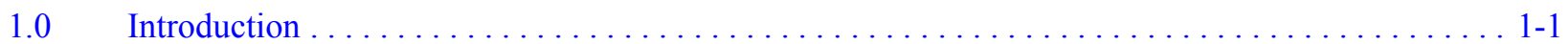

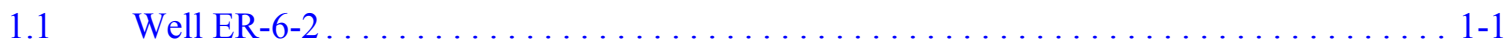

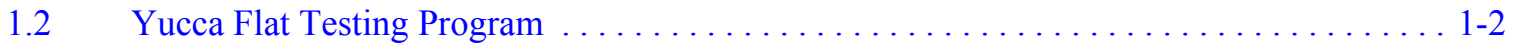

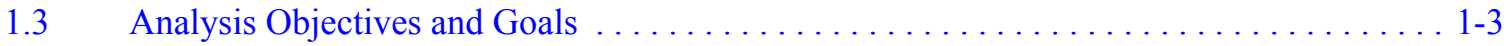

$2.0 \quad$ Equilibrium Well Hydraulics. . . . . . . . . . . . . . . . . . . . . . . . . $2-1$

$2.1 \quad$ Representative Formation Head. . . . . . . . . . . . . . . . . . . . . . . . 2-1

2.1.1 USGS Water-Level Monitoring . . . . . . . . . . . . . . . . . . . . 2-1

2.1.2 Depth-to-Water Measurements During Testing ................. 2-2

2.1.3 Static Formation Head Versus Static Water Level. . . . . . . . . . . . . . . 2-3

2.1.4 Potential Vertical Gradient . . . . . . . . . . . . . . . . . . . . . . . . . . 2 2-3

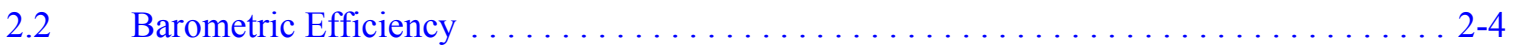

2.2.1 Ambient Monitoring Records . . . . . . . . . . . . . . . . .

2.2.2 Barometric Efficiency Analysis . . . . . . . . . . . . . . . . . . 2-4

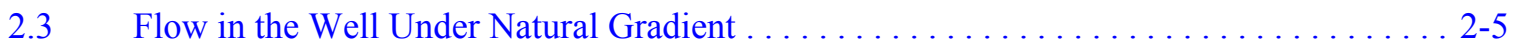

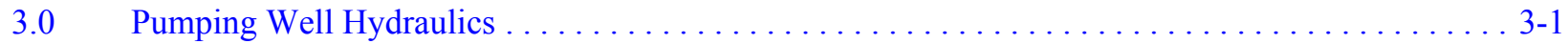

3.1 Processing of the Water-Level Monitoring Record . . . . . . . . . . . . . . $3-1$

$3.2 \quad$ Well Losses . . . . . . . . . . . . . . . . . . . . . . . . . . . . . . . . . . 3-2

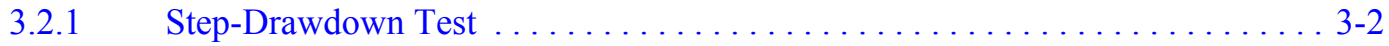

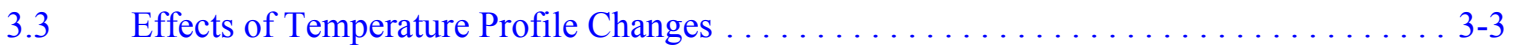

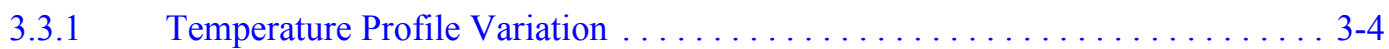

3.3.2 Effect of Temperature Profile Change on Measured

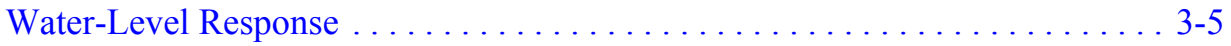

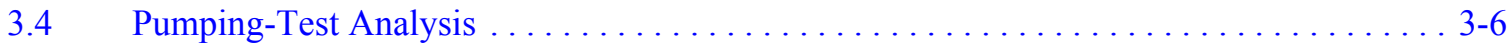

3.4.1 Method of Analysis. . . . . . . . . . . . . . . . . . . . . . . . . . 3-7

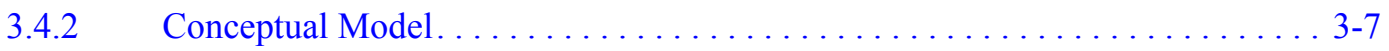

3.4.3 Hydraulic Response Analysis . . . . . . . . . . . . . . . . . . . . . 3-9

3.4.4 Best-Fit Parameter Estimates and Uncertainty . . . . . . . . . . . . . . . . 3-10

3.5 Interpretation and Analysis of Measured Discrete Production . . . . . . . . . . . . . 3-13

3.5.1 Flow Logging During Pumping . . . . . . . . . . . . . . . . . 3-13

3.5.2 Flow Profiles During Pumping . . . . . . . . . . . . . . . . . . . 3-15

3.5.3 Normalized Transmissivity Calculation ..................... 3-16

3.5.4 Interval Hydraulic Conductivities. . . . . . . . . . . . . . . . . . . . 3-17 


\section{Table of Contents (Continued)}

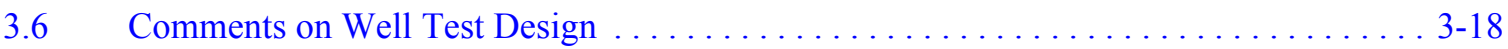

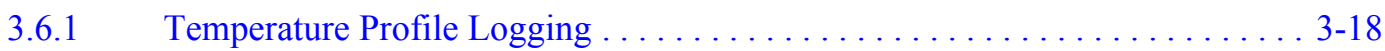

3.6.2 Pre-Test and Post-Test Monitoring Records.................. 3-19

3.6.3 Background Monitoring Record . . . . . . . . . . . . . . . . . 3-19

3.6.4 Pump Location . . . . . . . . . . . . . . . . . . . . . . . . . . .

3.6.5 TFM Measurements . . . . . . . . . . . . . . . . . . . . . 3-20

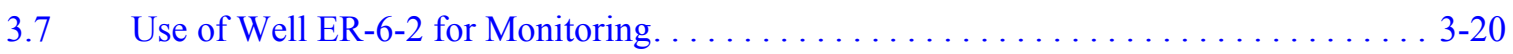

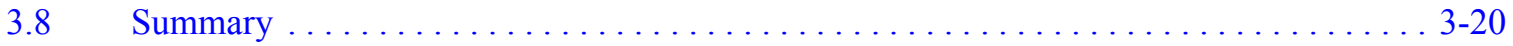

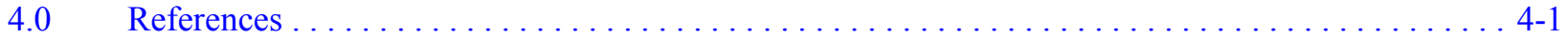




\section{List of Figures}

Number

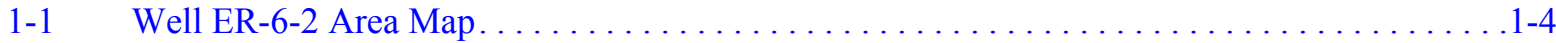

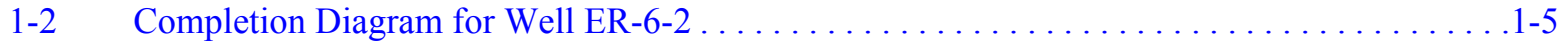

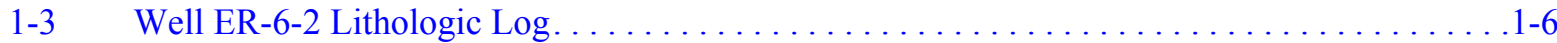

1-4 Geologic Cross Section from Well ER-6-2 to Well UE-1h . . . . . . . . . . . . . . . . .1-7

2-1 Graph of USGS Water-Level Monitoring for Well ER-6-2 . . . . . . . . . . . . . . . . .2-7

2-2 Overlay of Nonpumping Flow Profiles for Well ER-6-2 $\ldots \ldots \ldots \ldots \ldots \ldots \ldots \ldots \ldots \ldots \ldots$

2-3 Average 20 Feet/Minute Nonpumping Flow Profile for Well ER-6-2 . . . . . . . . . . . 2-9

3-1 Step-Drawdown Test Data and Fits for Early-Time (above) and Late-Time (below) of the Well Development Period . . . . . . . . . . . . . . . . 3-21

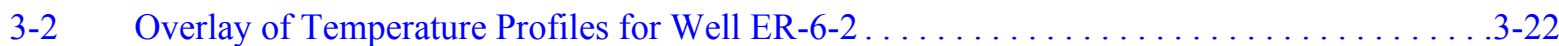

3-3 Synthetic Ambient and Pumping Temperature Profiles for Well ER-6-2 $\ldots \ldots \ldots \ldots \ldots$. $\ldots$.23

3-4 Log-Log Diagnostic Plot for the Complete ER-6-2 Drawdown Period . . . . . . . . . . . 3-24

3-5 ER-6-2 Constant-Rate Pump Test Response with Best-Fit Simulated Responses

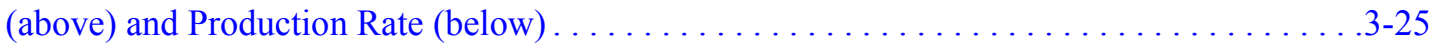

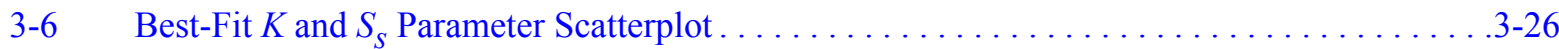

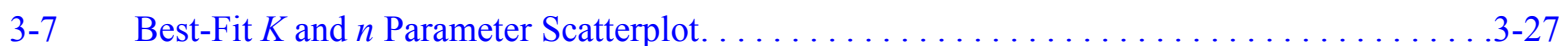

3-8 Cooper-Jacob Analysis of ER-6-2 Drawdown During the Observed

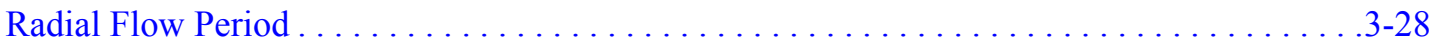

3-9 Fitting-Parameter Sensitivity Through the Complete ER-6-2 Pump-Test Record . . . . . . . . 3-29 


\section{List of Figures (Continued)}

Number

Title

Page

3-10 Overlay of Normalized Pumping Flow Profiles for Well ER-6-2 $\ldots \ldots \ldots \ldots \ldots \ldots \ldots$ 3-30

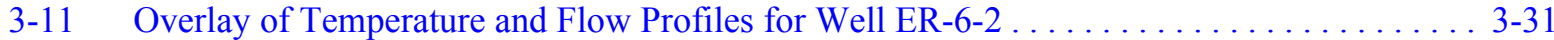

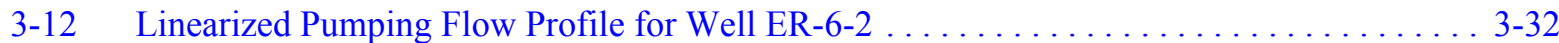




\section{List of Tables}

Number

Title

Page

1-1 Summary of Testing Program at Well ER-6-2 . . . . . . . . . . . . . . . . .

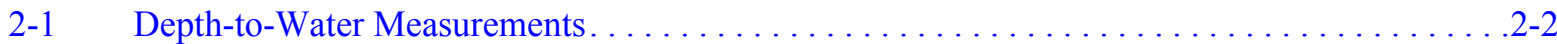

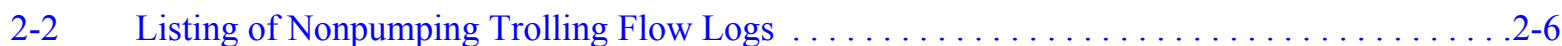

3-1 Step-Drawdown Tests. . . . . . . . . . . . . . . . . . . . . . . . . . . . . . . . . . . . 3-3

3-2 Best-Fit Hydraulic Parameters . . . . . . . . . . . . . . . . . . . . . . . . . . . . .3-11

3-3 Parameter Covariance - Correlation (bold text) Matrix . . . . . . . . . . . . . . . . . 3-12

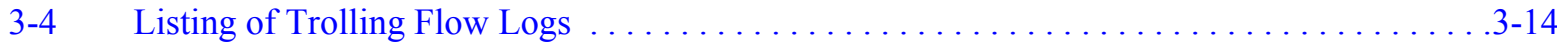

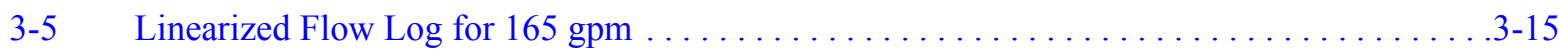

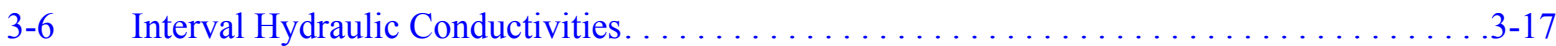




\section{List of Acronyms and Abbreviations}

\begin{tabular}{|c|c|}
\hline AMSL & Above mean sea level \\
\hline $\mathrm{BE}$ & Barometric efficiency \\
\hline bgs & Below ground surface \\
\hline $\mathrm{BN}$ & Bechtel Nevada \\
\hline${ }^{\circ} \mathrm{C}$ & Degrees Celsius \\
\hline CAU & Corrective Action Unit \\
\hline CS & Carbon-steel \\
\hline DOE & U.S. Department of Energy \\
\hline DRI & Desert Research Institute \\
\hline${ }^{\circ} \mathrm{F}$ & Degrees Fahrenheit \\
\hline fpm & Feet per minute \\
\hline $\mathrm{ft}$ & Foot \\
\hline $\mathrm{ft} / \mathrm{d}$ & Feet per day \\
\hline $\mathrm{ft}^{2} / \mathrm{d}$ & Square feet per day \\
\hline FY & Fiscal year \\
\hline gpm & Gallons per minute \\
\hline GTFM & Graph Theoretic Field Model \\
\hline HSU & Hydrostratigraphic unit \\
\hline in. & Inch \\
\hline K & Hydraulic conductivity \\
\hline LANL & Los Alamos National Laboratory \\
\hline LCA & Lower carbonate aquifer \\
\hline LLNL & Lawrence Livermore National Laboratory \\
\hline$n$ & Flow dimension \\
\hline NNSA/NSO & $\begin{array}{l}\text { U.S. Department of Energy, National Nuclear Security Administration Nevada } \\
\text { Site Office }\end{array}$ \\
\hline NTS & Nevada Test Site \\
\hline nSights & n-Dimensional Statistical Inverse Graphical Hydraulic Test Simulator \\
\hline psi & Pounds per square inch \\
\hline PXD & Pressure transducer \\
\hline$S_{S}$ & Specific storage \\
\hline Shaw & Shaw Environmental, Inc. \\
\hline SNJV & Stoller-Navarro Joint Venture \\
\hline
\end{tabular}




$\begin{array}{ll}\text { SFM } & \text { Spinner flowmeter } \\ \text { TD } & \text { Total depth } \\ \text { TFM } & \text { Thermal flowmeter tool } \\ \text { UCCU } & \text { Upper Clastic Confining Unit } \\ \text { UGTA } & \text { Underground Test Area } \\ \text { UNLV-HRC } & \text { University of Nevada, Las Vegas - Harry Reid Center } \\ \text { USGS } & \text { U.S. Geological Survey }\end{array}$




\subsection{Introduction}

This report documents the analysis of data collected for Well ER-6-2 during fiscal year (FY) 2004 Yucca Flat well development and testing program (herein referred to as the "testing program"). Participants in Well ER-6-2 field development and hydraulic testing activities were: Stoller-Navarro Joint Venture (SNJV), Bechtel Nevada (BN), Desert Research Institute (DRI), Los Alamos National Laboratory (LANL), Lawrence Livermore National Laboratory (LLNL), U.S. Geological Survey (USGS), and the University of Nevada, Las Vegas Harry Reid Center (UNLV-HRC). The analyses of data collected from the Well ER-6-2 testing program were performed by the SNJV.

\subsection{Well ER-6-2}

Well ER-6-2 was tested as part of FY 2004 activities for the U.S. Department of Energy (DOE), National Nuclear Security Administration Nevada Site Office (NNSA/NSO), Underground Test Area (UGTA) Project. Hydraulic testing was conducted to provide information on the hydraulic characteristics of the lower carbonate aquifer (LCA) hydrostratigraphic unit (HSU) (DOE/NV, 1997b). The well is located in southwestern Yucca Flat in Area 6 on the Nevada Test Site (NTS). Figure 1-1 shows the location of Well ER-6-2 within the Yucca Flat Corrective Action Unit (CAU). The well is located down-gradient from expended underground nuclear tests in central and northern Yucca Flat. Emplacement hole U-6a is the nearest underground nuclear test located approximately 6,846 feet (ft) to the northeast.

Well ER-6-2 was initially drilled in January 1993 to a total depth (TD) of 2,006 ft below ground surface (bgs) and then deepened by coring in July 1994 to a final TD of 3,430 ft bgs. The well completion is shown in Figure 1-2. The well is cased with 13.375-inch (in.) carbon-steel (CS) casing to a depth of $124 \mathrm{ft}$ bgs and then crossed over to 11.75 -in. CS casing from $124 \mathrm{ft}$ bgs to $1,740 \mathrm{ft}$ bgs. The well is open hole below the intermediate casing with hole diameters of 20 -in. to $1,898 \mathrm{ft}$ bgs, 10.625 -in. to $2,006 \mathrm{ft}$ bgs, and 5.5 -in to $3,430 \mathrm{ft}$ bgs.

The open borehole spans Paleozoic limestone (Bonanza King and Guilemette Formations) assigned to the lower carbonate aquifer (LCA) hydrostratigraphic unit (HSU) and shale (Chainman Shale) assigned to the upper clastic confining unit (UCCU) HSU as shown in the borehole geologic description in Figure 1-3. On this figure, the Bonanza King Fm. is designated CB, the Guilmette Fm. is designated DG, and the Chainman Shale is designated MDC. The section of the LCA penetrated by this well is mapped as LCA3, the overturned Yucca Flat upper plate of the LCA, which is the result of thrust faulting along the CP Thrust (DOE/NV, 1997b). The LCA3 is stratigraphically and lithologically the same as 
the LCA, and is only distinguished from the LCA by having been structurally displaced (see Figure 1-4). Hydraulic properties for the LCA3 are considered with those of the LCA, and therefore discussions regarding hydraulic properties will refer to the LCA.

Comprehensive details of the drilling and well completion program are documented in Yucca Flat ER-6-2 Well Data Report (DOE/NV, 1997a). Details of the development and testing program are documented in Yucca Flat Well ER-6-2 Data Report for Development and Hydraulic Testing (SNJV, 2005b).

\subsection{Yucca Flat Testing Program}

The hydraulic testing program included:

- Record of the ambient water-level response

- Well development, including step-drawdown tests

- Flow and temperature logging under nonpumping conditions

- Flow and temperature logging during pumping

- $\quad$ Single-well constant-rate pumping test and recovery monitoring

An overview of the testing program schedule is shown in Table 1-1.

Table 1-1

Summary of Testing Program at Well ER-6-2

\begin{tabular}{|c|c|c|c|}
\hline Activity & Start Date & Finish Date & $\begin{array}{l}\text { Duration in } \\
\text { Days* }^{*}\end{array}$ \\
\hline Mobilize equipment & $6 / 21 / 2004$ & $6 / 24 / 2004$ & 4 \\
\hline $\begin{array}{l}\text { Install access line, pump, and monitoring equipment, and conduct } \\
\text { pump function test }\end{array}$ & $7 / 8 / 2004$ & $7 / 14 / 2004$ & 4 \\
\hline $\begin{array}{l}\text { Conduct well development and run temperature and spinner } \\
\text { flowmeter logs }\end{array}$ & $7 / 14 / 2004$ & $7 / 21 / 2004$ & 8 \\
\hline Conduct pretest water-level monitoring & $7 / 21 / 2004$ & $7 / 26 / 2004$ & 6 \\
\hline Conduct constant-rate test & $7 / 26 / 2004$ & $8 / 4 / 2004$ & 10 \\
\hline Collect groundwater characterization samples & $8 / 4 / 2004$ & $8 / 4 / 2004$ & 1 \\
\hline Conduct post-test water-level monitoring & $8 / 4 / 2004$ & $8 / 9 / 2004$ & 6 \\
\hline Conduct post-test temperature log & $8 / 12 / 2004$ & $8 / 12 / 2004$ & 1 \\
\hline Remove the well access line and pump & $8 / 25 / 2004$ & 8/30/2004 & 6 \\
\hline Install the low-volume sampling pump and conduct function test & $8 / 30 / 2004$ & $8 / 31 / 2004$ & 2 \\
\hline Demobilize equipment from the site & $8 / 31 / 2004$ & $9 / 1 / 2004$ & 2 \\
\hline
\end{tabular}

${ }^{*}$ Actual duration of specific site activity.

Note: Gaps between activities indicate days when no activities took place. 


\subsection{Analysis Objectives and Goals}

The testing program was designed to provide local hydrologic conditions and HSU hydraulic parameters information for use in the CAU-scale flow and transport models. The objective of the analysis is to maximize the hydrogeologic information drawn from collected data. Specifically, both composite and interval-specific formation hydraulic parameters are estimated.

Section 2.0 of this report discusses the analysis of the nonpumping (pseudo-static) natural-gradient well hydrology. Section 3.0 discusses the well hydraulics during pumping and includes analysis of the constant-rate test and the flow logging. Both composite and interval-specific hydraulic parameters for the well are presented. Section 3.0 includes comments on the design of the testing program components 


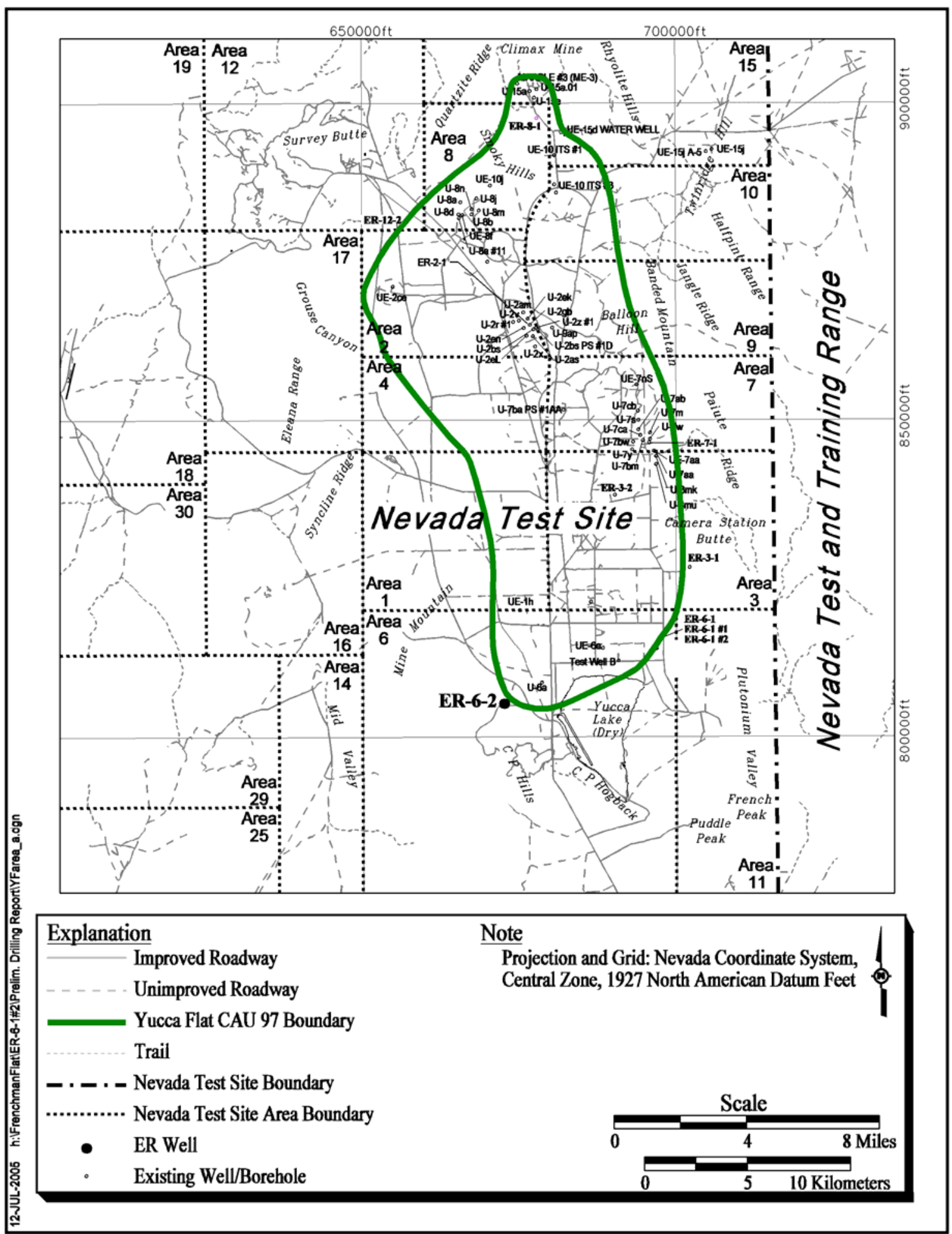

Figure 1-1

Well ER-6-2 Area Map 


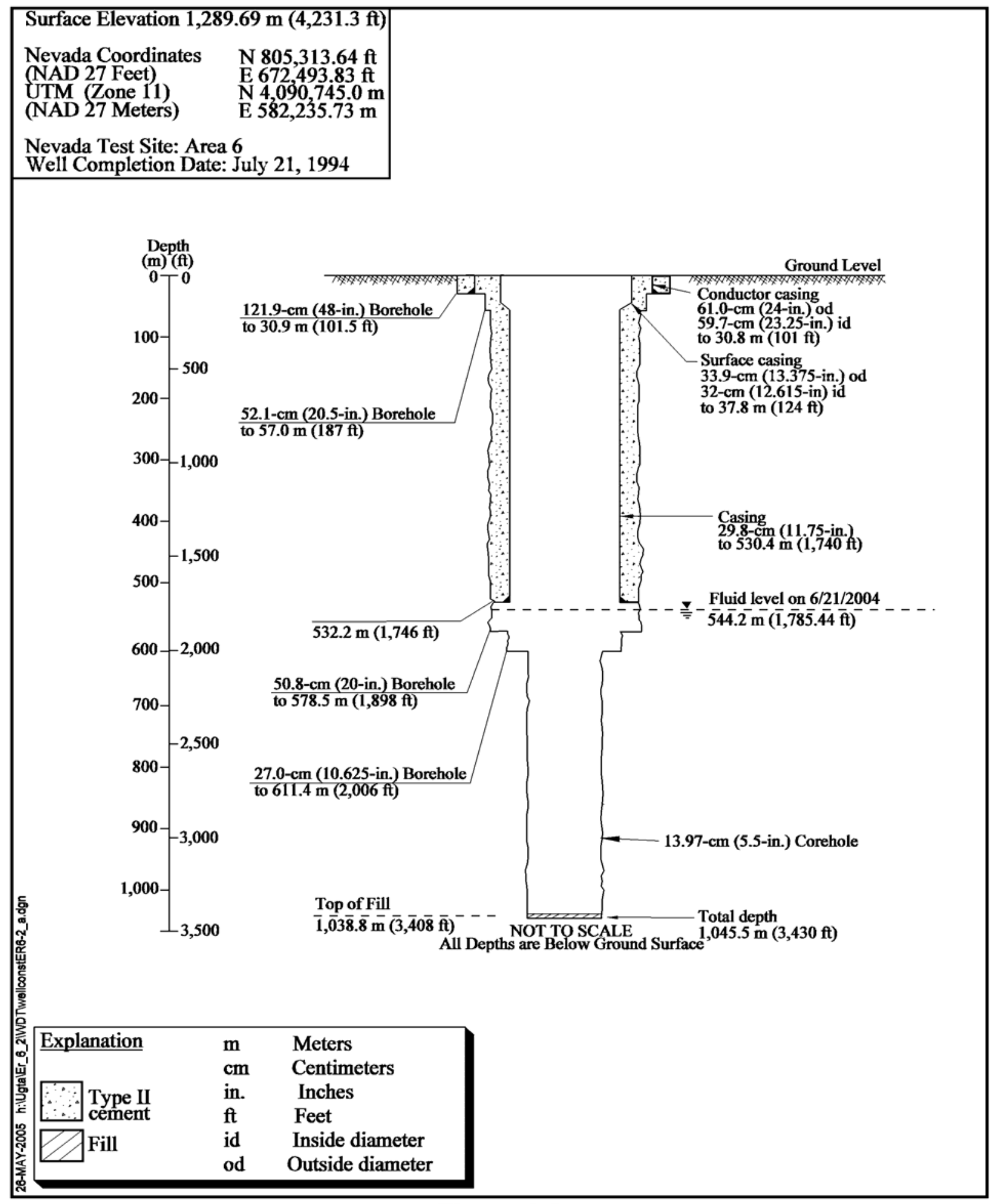

Figure 1-2

Completion Diagram for Well ER-6-2 


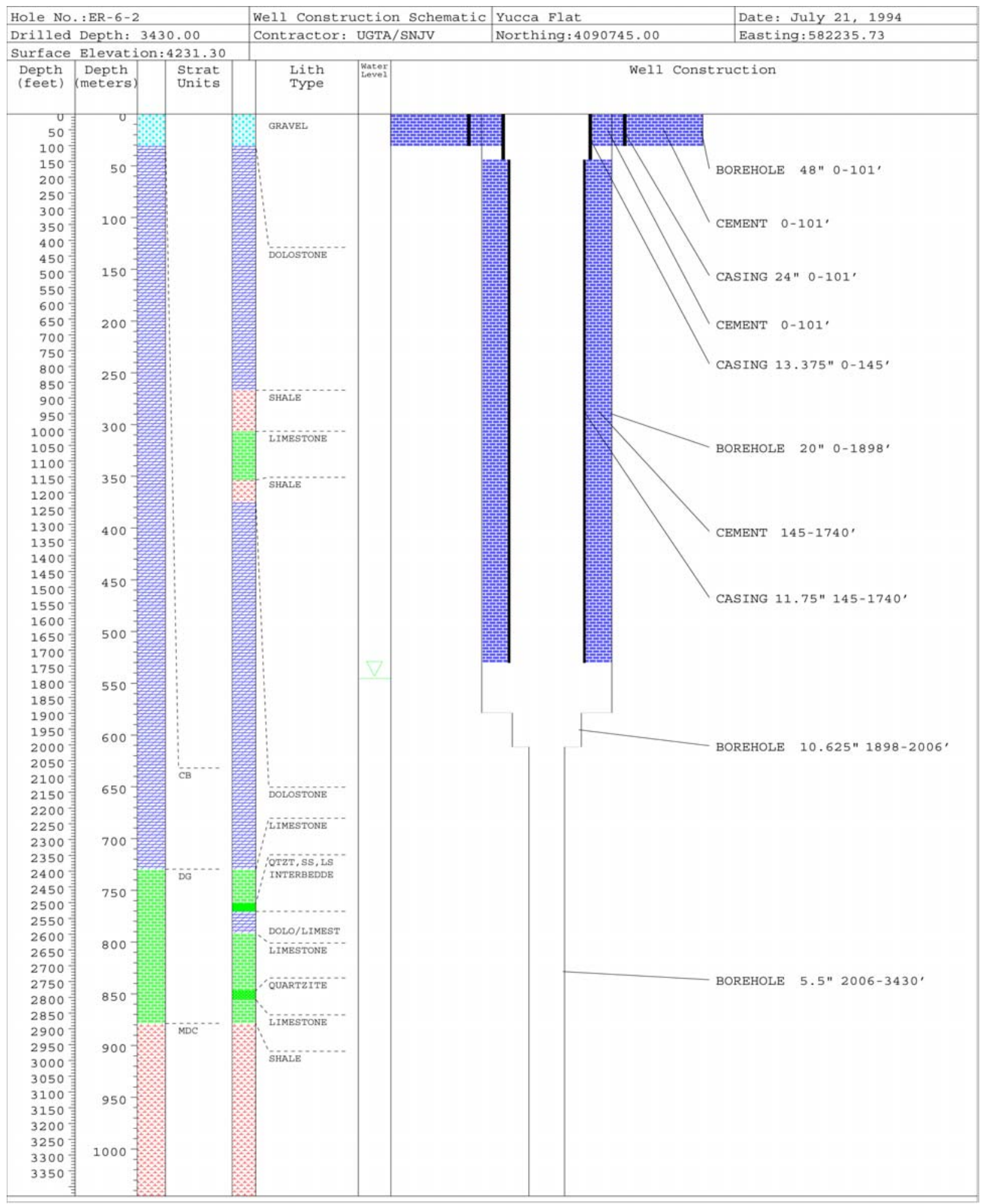

Figure 1-3

Well ER-6-2 Lithologic Log 


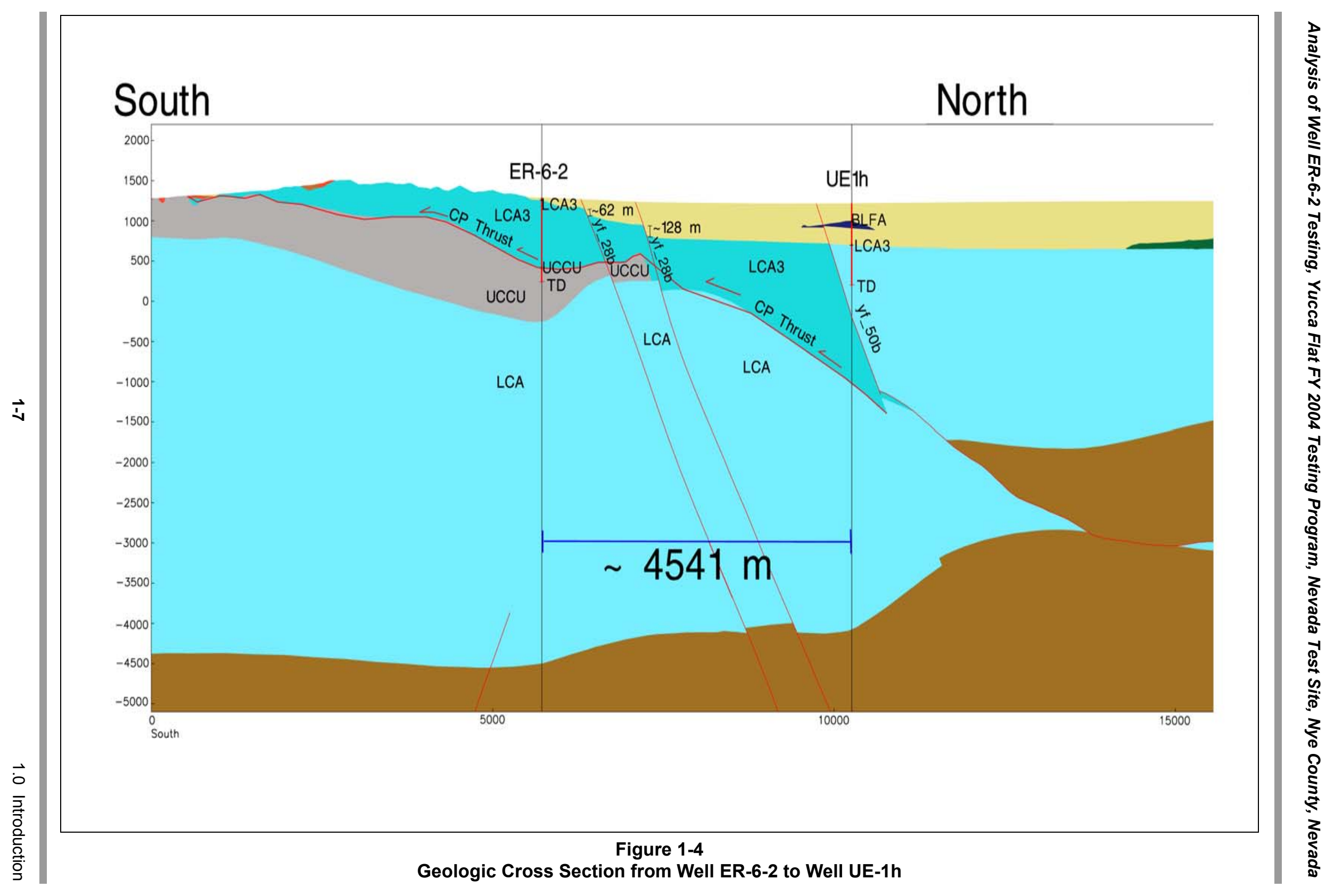




\subsection{Equilibrium Well Hydraulics}

This section discusses Well ER-6-2 hydraulics in the static, nonpumping condition. Formation hydraulic properties are estimated through interpretation of the formation pressure response to well production; however, it is important to first quantify hydraulic characteristics of the well under equilibrium, nonpumping conditions that influence the measured response to production. The relevant characteristics include the representative head for the well completion, static formation pressure for testing, equilibrium borehole temperature and density profiles, vertical gradient within the completion interval and resultant vertical circulation, and discrete-interval horizontal flow into or out of the formation.

\subsection{Representative Formation Head}

Formation head, hydraulic head expressed as equivalent elevation head, is of interest for several purposes. The head value may be used for mapping of the formation head across an area of interest to determine head gradients and to infer the direction of groundwater flow. It is also necessary to know if the well is in equilibrium at the time of testing and to determine when it has recovered to an equilibrium condition. Water-level monitoring information collected periodically on schedules with different time scales allows the evaluation of different components of the natural variation of formation head such as responses to barometric pressure variation, earth tides, background trends, and responses to imposed stress during testing. Water-level information is available for ER-6-2 since the initial well completion, collected both by the ER contractor and by USGS.

\subsubsection{USGS Water-Level Monitoring}

Water levels have been measured by the USGS since well re-completion in July 1994, and are tabulated on the National Water Inventory System website (USGS, 2005). Figure 2-1 is a graph of the USGS water-level measurements. Water-level elevation has trended upward from about 2,444.6 ft above mean sea level (AMSL) in September 1994 to 2,447.6 ft AMSL in May 2004, just before well development activities began. Measurements made subsequent to testing show continuation of the long-term trend. This trend should be considered when using the formation head measurements reported in this document. 


\subsubsection{Depth-to-Water Measurements During Testing}

During the testing program, discrete depth-to-water measurements were made using an E-tape calibrated to an accuracy of $0.01 \mathrm{ft}$ per $1,000 \mathrm{ft}$. However in practice, water-level measurements are generally only repeatable within $0.1 \mathrm{ft}$ per $1,000 \mathrm{ft}$ between independent measurements (complete removal and reinsertion) using the same instrument. As mentioned in Section 2.1, formation head may vary continuously, and there is no way to separate actual variation in formation head from uncertainty in the measurements at this level.

Discrete water-level (i.e., depth-to-water) measurements recorded during the testing program are shown in Table 2-1. Note that the values for Depth-to-Water and Water-Level Elevation in this table differ from those in the ER-6-2 Testing Data Report because a correction for borehole deviation has been incorporated. The measured water level is primarily a function of the pressure within the completion formation. However, the water surface elevation can be affected by barometric fluctuation, earth tides, and the temperature-density profile of the water column in the completion interval. The water level measured on June 21, 2004, was measured before conducting downhole operations. The remaining four water-level measurements were collected during the testing program but not in close association with any pumping. The water-level measurements have not been corrected for barometric pressure differences or water column temperature profile variations. However, there is little variation in the barometric pressure measured at the time of the water-level measurements. Temperature profile variation is probably not a significant factor because the measurements were all made after time was allowed since pumping for equilibration. Earth tides produce maximum water-level variations of about $0.1 \mathrm{ft}$ in this well (Figure 3-1, SNJV 2005b), and the measurement uncertainty is about $0.18 \mathrm{ft}$. As shown in Table 2-1, all measurements were within $0.35 \mathrm{ft}$. Considering the uncertainty due to the various factors, the independent measurements are almost identical suggesting that these water levels are generally representative of equilibrium conditions during the testing program. As discussed in Section 3.0, this well is highly transmissive, and it is reasonable that the formation head would recover rapidly after pumping to near equilibrium.

Table 2-1

Depth-to-Water Measurements

\begin{tabular}{|c|c|c|c|c|c|c|}
\hline \multirow{2}{*}{\begin{tabular}{|c|} 
Date \\
(month/day/year)
\end{tabular}} & \multirow{2}{*}{$\begin{array}{c}\text { Time } \\
\text { (hour:minute) }\end{array}$} & \multicolumn{2}{|c|}{$\begin{array}{l}\text { True Depth-to-Water } \\
\text { Below Ground Surface }\end{array}$} & \multirow{2}{*}{$\begin{array}{c}\begin{array}{c}\text { Barometric } \\
\text { Pressure }\end{array} \\
\text { Millibar }\end{array}$} & \multicolumn{2}{|c|}{$\begin{array}{l}\text { Water-Level } \\
\text { Elevation }^{a}\end{array}$} \\
\hline & & Feet & Meters & & Feet & Meters \\
\hline \multicolumn{7}{|c|}{ Well ER-6-2 } \\
\hline $6 / 21 / 2004$ & $15: 40$ & $1,783.47$ & 543.60 & $\mathrm{~N} / \mathrm{A}$ & $2,447.79$ & 746.09 \\
\hline $7 / 14 / 2004$ & $09: 45$ & $1,783.68$ & 543.66 & 873.49 & $2,447.58$ & 746.02 \\
\hline $7 / 18 / 2004$ & $09: 45$ & $1,783.48$ & 543.60 & 873.98 & $2,447.78$ & 746.08 \\
\hline $7 / 21 / 2004$ & $13: 00$ & $1,783.33$ & 543.56 & 871.01 & $2,447.93$ & 746.13 \\
\hline $8 / 9 / 2004$ & $16: 15$ & $1,783.53$ & 543.62 & 872.66 & $2,447.73$ & 746.07 \\
\hline
\end{tabular}

a Reference Datum: 1,289.69 meters (4,231.26 feet) above mean sea level datum

$\mathrm{N} / \mathrm{A}=$ Not available 


\subsubsection{Static Formation Head Versus Static Water Level}

Static formation pressure measured as the head of the water column surface within the well is equivalent to the composite equilibrium pressure of the formation(s) accessed by the well completion. The well completion effectively connects intervals within the formation of varying pressure resulting in formation static pressure that is the average of the interval pressures weighted by the hydraulic conductivity of the intervals. The static formation pressure represents the starting head for the pressure response to hydraulic stress, and the head that recovering formation pressure approaches with time.

In theory, determination of the static formation pressure appears straightforward typically based on depth-to-water measurements and/or in situ pressure transducer (PXD) measurements. However, in practice the static formation pressure is difficult to characterize for two reasons: The static formation pressure may vary continuously with time as a function of several natural processes, and measurements are not typically made at the depth of the completion interval for practical reasons. Discrete depth-to-water measurements do not capture the continuous variation, but continuous measurements made by a PXD/datalogger system can capture the composite variation. The continuous formation pressure variation during static conditions reflects earth tide and barometric fluctuations as well as short- and long-term flow system trends. The former two effects can be identified in the monitoring record and removed with processing based on additional measurements while the latter two effects require an independent background record during the nonequilibrium test period. Variable density along the water column with depth due to temperature variation and water quality variation results in uncertain estimation of the formation head at the completion interval. The uncertainty resulting from these factors often cannot be resolved because sufficient information is not available. In the following sections, basic information on static formation pressure is addressed through analysis of depth-to-water measurements, predevelopment water-level monitoring, and barometric efficiency $(\mathrm{BE})$.

\subsubsection{Potential Vertical Gradient}

Before deepening the well from 2,006 ft bgs to 3,430 ft bgs in July 1994, the measured depth-to-water on September 8, 1993, was 1,789.49. After deepening, the first measurement by the USGS on October 12, 1994, was 1,786.66. This almost 3-ft difference between the measured water levels before and after recompletion may reflect an upward vertical gradient across the additional 1,424 ft of formation added to the well completion interval during recompletion. This increase in water level exceeds the water-level trend observed during the course of post-recompletion monitoring. However, the few pre-coring water-level measurements available may not provide a representative basis for evaluating such a gradient. 


\subsection{Barometric Efficiency}

The BE of the well is used in the analyses of the hydraulic tests to refine hydraulic response data by removing atmospheric-induced components unrelated to the test. The importance of determining the correct value for barometric efficiency is somewhat dependent on the magnitude of the drawdown of the well during testing; the greater the drawdown, the less influence the barometric correction has on the measured formation response. However, where small-scale water-level changes are being interpreted, which is true for Well ER-6-2, correction for barometric variation during the monitoring period is important. Barometric efficiency is determined from continuous monitoring records of the well water level fluctuations and barometric pressure variation. The primary purpose for determining $\mathrm{BE}$ is for use in removing the effect of barometric pressure variation from the drawdown response record used for analysis of the constant-rate test and is treated as a fitting parameter for maximum smoothing of that record.

\subsubsection{Ambient Monitoring Records}

Barometric efficiency was assessed using two record periods: one just after development and prior to the constant-rate test, and the other after recovery from the constant-rate test drawdown. The head in Well ER-6-2 recovers quickly after production is stopped and appears to have been in near equilibrium during these records. However, there is a substantial change in the temperature profile in the water column during pumping resulting in water-level changes due to thermal expansion, which is discussed later in Section 3.3. Both ambient water-level monitoring records were recorded while the temperature was equilibrating back to the ambient temperature profile, resulting in nonlinear components to the trends in the head data which introduce additional uncertainty in the analysis. The short monitoring records collected do not include large variations in barometric pressure, and consequently do not provide a good basis for evaluating BE.

\subsubsection{Barometric Efficiency Analysis}

The methodology used for determining BE consists of overlaying the water-level record with the barometric pressure record after converting barometric data to consistent units and inverting the trace. The processed barometric trace is trended and scaled until a best-fit match to the water-level record is determined. The trending represents water-level trends not related to barometric response allowing the barometric component of the responses to overlay the barometric record; the scaling factor is equal to the barometric efficiency. This method assumes that the water level in the well is in equilibrium with the groundwater head. Nonlinear water-level trends are problematic. The best result using this methodology requires that the record includes longer-term changes in barometric pressure than the diurnal and semidiurnal fluctuations with magnitude substantially greater than those fluctuations. This requirement is necessary to separate the barometric response of the well from earth tide-related fluctuations and to avoid the phase-shift uncertainty of short-term barometric responses. 
The determination of BE is reported in Section 3.1 of the testing data report (SNJV, 2005b) for two different monitoring records. The best fit was obtained with $\mathrm{BE}$ values of 0.82 and 1.0, respectively. The lower efficiency was determined from the pre-development record while the higher efficiency was found post-testing. This difference could be the result of improved connection of the wellbore to the formation following development of the well. However, the short records and temperature equilibration effects result in substantial uncertainty in the derived BE values, so the actual change may be somewhat different from the apparent change.

An independent assessment of BE was done in conjunction with data files prepared for the analysis of the constant-rate test. This is discussed in Section 3.1.

\subsection{Flow in the Well Under Natural Gradient}

Flow in the well under natural gradient conditions was measured with the DRI impeller flow tool to provide direct information on the discrete location or profile and direction of water production. This tool has a lower measurement limit of 2.5 feet per minute (fpm) and is usually used in conjunction with the DRI thermal flowmeter tool (TFM), which has a lower measurement limit of $0.1 \mathrm{fpm}$. However, measurements with the TFM were not made due to difficulties in running the TFM tool downhole below the ledge formed by the change in borehole diameter at 2,006 ft bgs. The interpretation of temperature logs is used in conjunction with borehole flow measurements for identification of flow under ambient conditions.

Table 2-2 lists the trolling flow log runs when the well was not being pumped. All logs were run through the entire extent of the accessible interval, 2,030 to $3,375 \mathrm{ft}$ bgs. However, the open borehole extended above 2,030 to 1,746 ft bgs. This section of the open borehole was inaccessible to logging, because the pump was installed to a depth of $1,952 \mathrm{ft}$ bgs, and the access line hung to 2,017 ft bgs. Logs were run at line speeds of 20,40, and $60 \mathrm{fpm}$ both downward and upward. The multiple runs are used in a calibration process. Desert Research Institute typically provides calibrated data at $0.2 \mathrm{ft}$ resolution; however, the calibrated data was not available at the time of this analysis. A description of the calibration methods and raw data manipulation (conversion of the measured spinner rate to interval flow rates) is reported by DRI in their yearly logging reports (see Oberlander and Russell, 2003).

Figure 2-2 shows an overlay of the six flow logs run during a nonpumping period to display the differences between these logs. These logs were run at progressively increasing line speeds $(20,40,60 \mathrm{fpm})$, first downward and then upward. The logs are significantly different from each other with differences appearing to be somewhat related to the logging direction and to the line speed. The two logs run at the lowest line speed indicate the lowest flow, in the range of 1-2 gallons per minute (gpm), but in opposite directions. Figure 2-3 shows the average of the two logs, which suggests that there is downhole flow of a maximum rate of approximately $1 \mathrm{gpm}$ across the production interval identified in the flow logs during pumping. There appears to be little flow above or below the 
Table 2-2

Listing of Nonpumping Trolling Flow Logs

\begin{tabular}{|c|c|c|c|c|c|}
\hline Run Number & Date & $\begin{array}{c}\text { Run } \\
\text { Direction }\end{array}$ & $\begin{array}{c}\text { Targeted } \\
\text { Line Speed } \\
(\text { fpm) }\end{array}$ & $\begin{array}{c}\text { Surface } \\
\text { Discharge } \\
\text { (gpm) }\end{array}$ & $\begin{array}{l}\text { Start - Finish } \\
\text { (ft bgs) }\end{array}$ \\
\hline er62mov01a & \multirow{6}{*}{$7 / 18 / 2004$} & Down & 20 & 0 & $2,030-3,375$ \\
\hline er62mov02a & & Up & 20 & 0 & $3,375-2,030$ \\
\hline er62mov03a & & Down & 40 & 0 & $2,030-3,375$ \\
\hline er62mov04a & & Up & 40 & 0 & $3,375-2,030$ \\
\hline er62mov05a & & Down & 60 & 0 & $2,030-3,375$ \\
\hline er62mov06a & & Up & 60 & 0 & $3,375-2,030$ \\
\hline
\end{tabular}

fpm $=$ Feet per minute

$\mathrm{ft}$ bgs $=$ Feet below ground surface

$\mathrm{gpm}=$ Gallons per minute

production interval. However, these rates are below the lower measurement limit of the flow logging tool and may not be accurate. This would indicate downward circulation within the permeable section of the open borehole, presumably in response to a natural downward vertical gradient. However this is in conflict with the apparent upward gradient discussed in Section 2.1.4. The data is inconclusive regarding flow in the borehole under the natural gradient. 


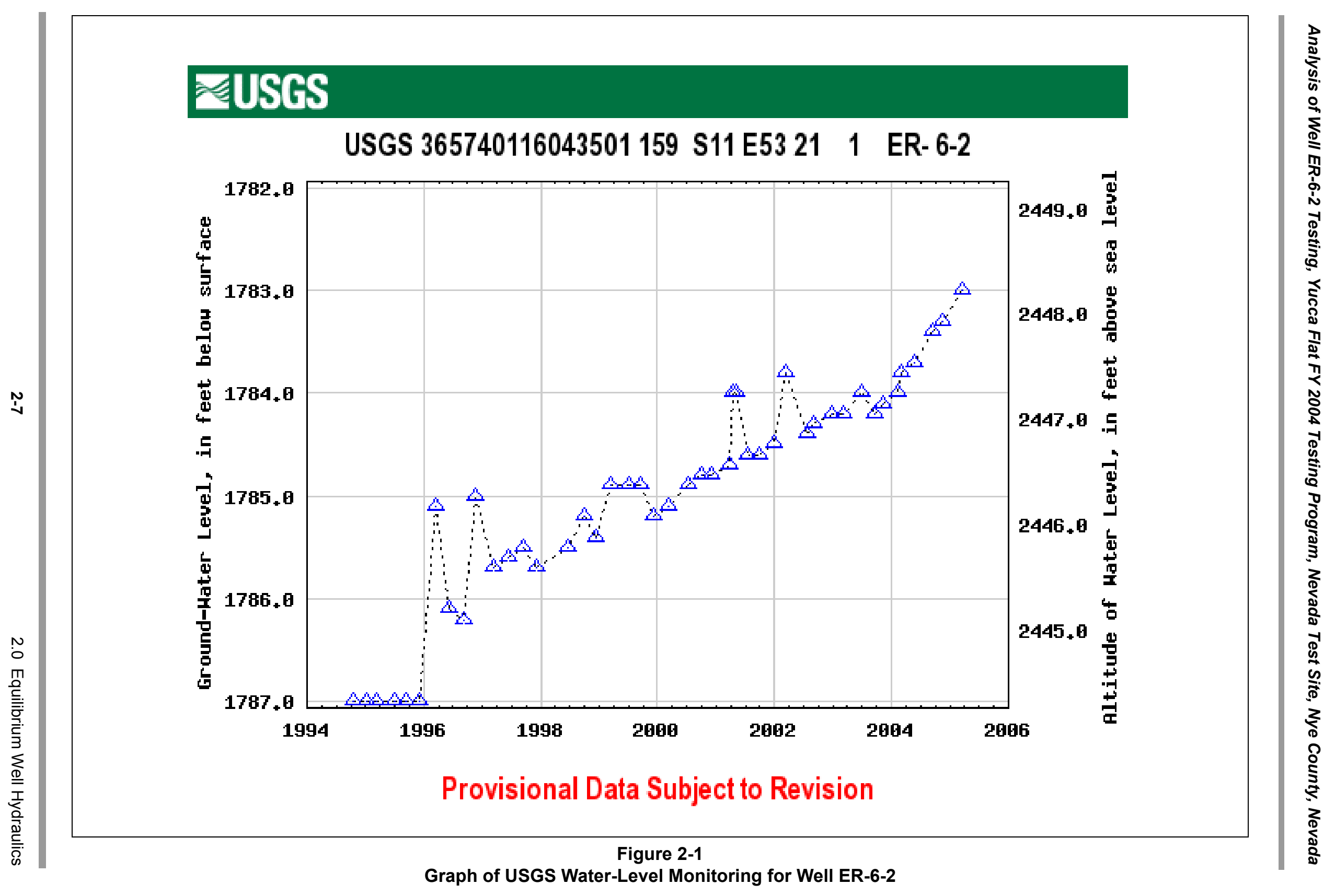




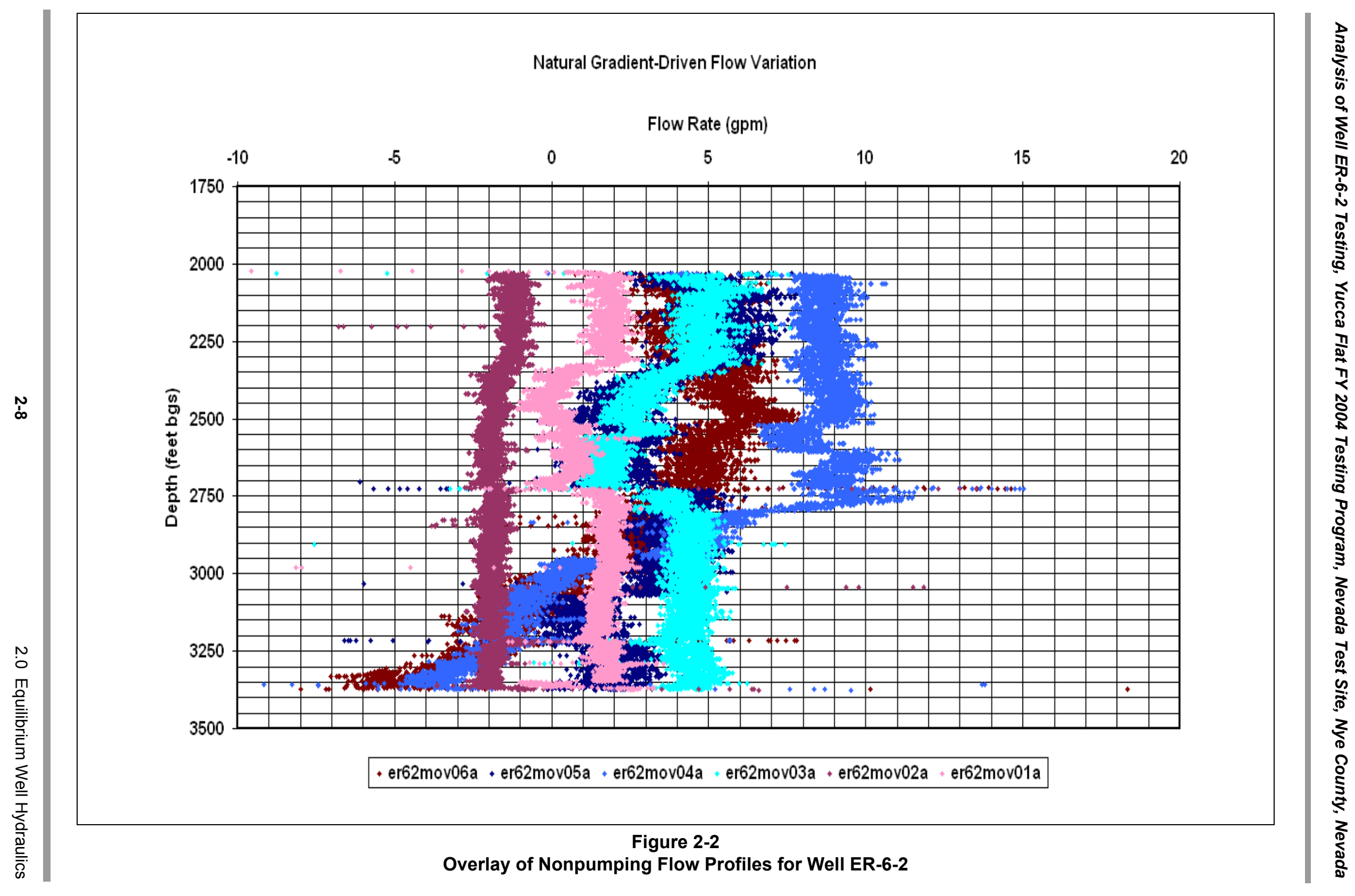




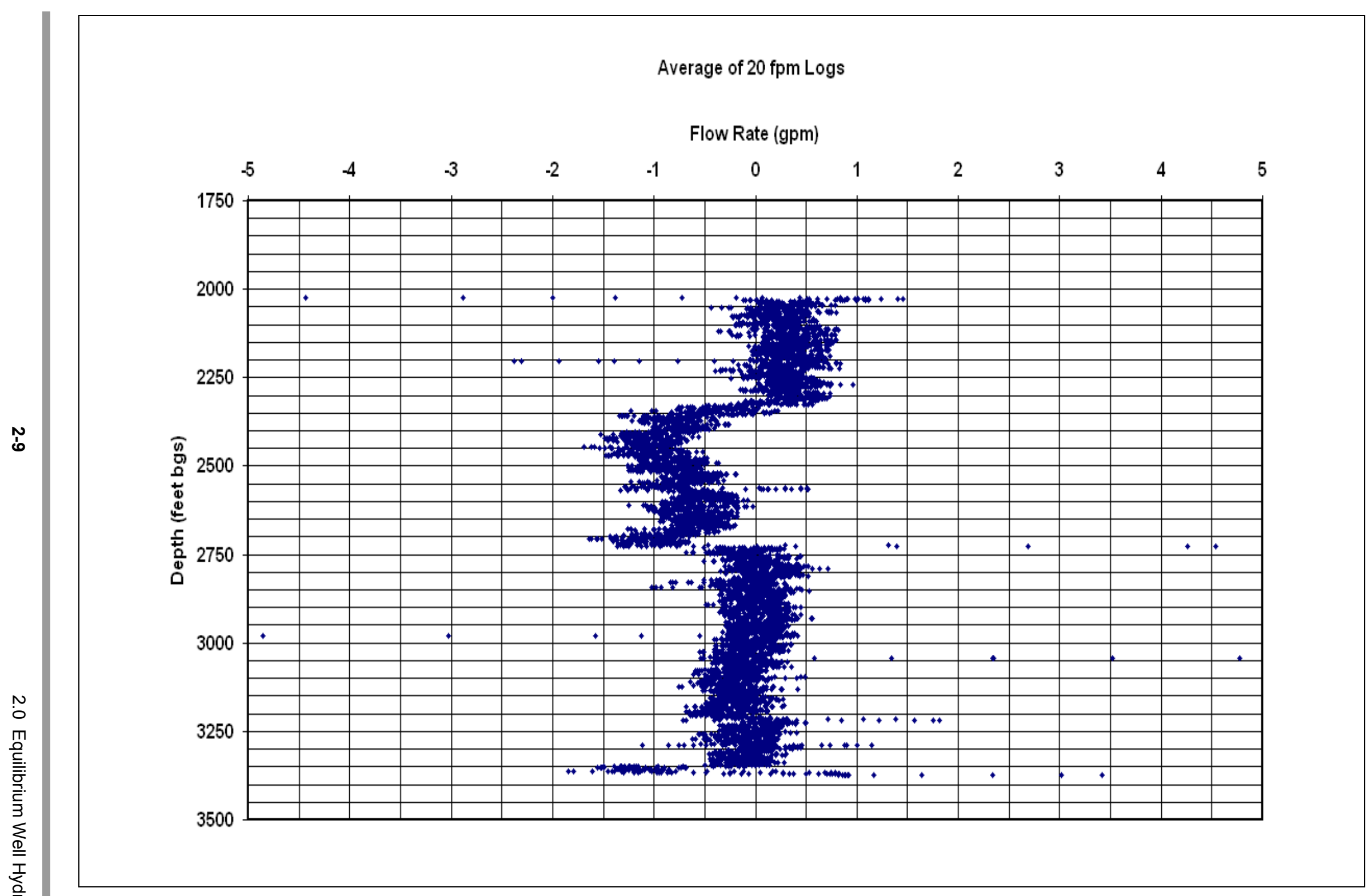

Figure 2-3

Average 20 Feet/Minute Nonpumping Flow Profile for Well ER-6-2 


\subsection{Pumping Well Hydraulics}

There are a number of steps in the analysis of the constant-rate pumping test. The drawdown and recovery response record is processed to remove the effects of barometric pressure variation, earth tides, and background water-level trends. The pumping well hydraulics are assessed to determine the magnitude of well losses so corrections can be made to attribute the correct proportion of the drawdown to the formation response. In cases where there are temperature profile changes in the water column resulting from pumping, the magnitude of the change must be ascertained and considered in analysis. After analysis of the pumping test to determine the composite transmissivity of the formation tested, the discrete production distribution measured from the flow logs is used to determine the hydraulic conductivities of distinct flow intervals across the completion.

\subsection{Processing of the Water-Level Monitoring Record}

The constant-rate test water-level monitoring record was processed using a spreadsheet tool provided by the USGS (Halford, 2005) for evaluation that simultaneously removes the effects of barometric pressure variation, earth tides and background water-level trends. Records for barometric pressure variation and water-level monitoring of a background well, in addition to an internal earth-tide generator, are used in the spreadsheet to create a synthetic water-level record to simulate the expected water-level record for the test period as if the well had not been pumped. The drawdown response during the test is then calculated as the difference between the actual and simulated records. Use of this tool proved effective in removing water-level response components (background trends and earth tides) not associated with the test from the drawdown response which substantially smoothed the pumping response record. The barometric record used can be found in the testing data report for ER-6-2 (SNJV, 2005b), and the monitoring record for Well UE-1h can be found in the testing data report for the ER-6-1 MWAT (SNJV, 2005a).

A water-level monitoring record for Well UE-1h, which was being monitored for another test (ER-6-1 MWAT-TT), was available and was determined to meet criteria for use as a background well. This well is also located in southwest Yucca Flat about $14,898 \mathrm{ft}$ to the north-northwest of ER-6-2. It is completed in the LCA and thought to be in continuous connection with the block of LCA3 in which ER-6-2 is completed. However, there are three major intervening faults between the two wells. Figure 1-4 showed the relationship of the UE-1h completion interval to that of ER-6-2. The UE-1h record showed no apparent response to either test. The lack of response is presumed to be due to a combination of distance from the pumping well, such that a pressure response did not propagate to 
UE-1h during the period of the test, and to poor hydraulic connection across the intervening faults. The main quality required for the background record used for correction is the capture of background water-level trend(s) occurring in the tested formation, which are generally observed on a scale much larger than the separation of these two wells. The composite barometric response, earth tides, and background trends identified from UE-1h were removed from the ER-6-2 hydraulic testing data record used for analysis (presented in Section 3.4).

\subsection{Well Losses}

The drawdown observed in the well in response to pumping is comprised of aquifer drawdown and well losses resulting from the water flow into the well and up the borehole to the pump. Transmissivity is directly proportional to the magnitude of aquifer drawdown. The partitioning of the total drawdown into its components provides a better understanding of the hydraulics of water production and better estimates of aquifer properties. Aquifer drawdown can be observed directly in observation wells near a pumping well; however, such wells were not available near Well ER-6-2. The step-drawdown test analysis is used to determine the laminar and turbulent components of drawdown. The laminar component of well drawdown is attributed to aquifer drawdown via Darcian flow; the turbulent component is primarily attributed to wellbore skin losses (entrance losses) and flow losses due to friction along the wellbore up to the pump intake.

\subsubsection{Step-Drawdown Test}

As recorded, additional drawdown in water level from increasing well production rates is larger than would be expected from resistance to Darcian flow in the aquifer alone. Turbulent head losses, both in the well and the near-well environment (e.g., gravel pack, formation skin, near-well, and intersecting fractures) increase with approximately the pumping rate square. Some treatments of nonlinear losses allow the well power loss component to vary, producing values from one to near three. However, in this analysis it is assumed that nonlinear well losses are primarily internal flow losses that vary according to the second power of the production rate; therefore, the Hantush-Bierschenk methodology is applied (Kruseman and de Ridder, 1990). The equation for drawdown with nonlinear well losses during a step-drawdown test is given below:

$$
S_{w}=B Q_{n}+C Q_{n}^{2}
$$

where
$S_{w} \quad=\quad$ The drawdown in the well
$Q_{n} \quad=$ The production rate at step $n$
$B=$ The linear coefficient
$C=$ The nonlinear coefficient 
Dividing both sides of Equation 3-1 by $\mathrm{Q}_{\mathrm{n}}$ produces a linear equation suitable for linear regression and provides the inverse solutions for the linear and nonlinear coefficients.

Two step-drawdown tests were conducted. The first was conducted early during development, and the second late in development. The analysis of these tests are reported in Section 2.6.3 of the ER-6-2 Well Development and Testing Data Report (SNJV, 2005b). Figure 3-1 shows plots of the step drawdowns for the early- and late-time tests, respectively, and Table 3-1 shows the results of the test analyses. The resultant equations were:

$$
\begin{array}{ll}
\text { - } & \mathrm{S}_{\mathrm{w}} / \mathrm{Q}=7.17 \times 10^{-5} \mathrm{Q}+7.40 \times 10^{-3} \\
\text { - } & \mathrm{S}_{\mathrm{w}} / \mathrm{Q}=7.08 \times 10^{-5} \mathrm{Q}+7.33 \times 10^{-3}
\end{array}
$$

The tests produced almost identical results and indicate substantial nonlinear losses; about 60 percent of the total drawdown at $165 \mathrm{gpm}$ is attributed to well flow losses. The hydraulic testing data are corrected for nonlinear losses in their analysis (presented in Section 3.4).

Table 3-1

\begin{tabular}{|c|c|c|c|c|c|}
\hline $\begin{array}{l}\text { Production Rate } \\
\text { (Q) (gpm) }\end{array}$ & $\underset{(\mathrm{ft})}{\operatorname{Drawdown}}\left(\mathrm{S}_{\mathrm{W}}\right)$ & $\begin{array}{c}\mathrm{S}_{\mathrm{W}} / \mathrm{Q} \\
(\mathrm{ft} / \mathrm{gpm})\end{array}$ & $\begin{array}{c}\text { Calculated } \\
\text { Nonlinear } \\
\text { Losses } \\
\text { (ft) }\end{array}$ & $\begin{array}{c}\text { Calculated } \\
\text { Linear } \\
\text { Losses } \\
\text { (ft) }\end{array}$ & $\begin{array}{c}\text { Calculated } \\
\text { Total Losses } \\
\text { (ft) }\end{array}$ \\
\hline \multicolumn{6}{|c|}{ Test $1,7 / 15 / 2004$} \\
\hline 75.61 & 0.98 & 0.0129524 & 0.41 & 0.56 & 0.97 \\
\hline 121.46 & 1.92 & 0.0158428 & 1.06 & 0.90 & 1.96 \\
\hline 165.73 & 3.22 & 0.0194179 & 1.97 & 1.23 & 3.20 \\
\hline \multicolumn{6}{|c|}{ Test $2,7 / 17 / 2004$} \\
\hline 75.48 & 0.96 & 0.0126784 & 0.40 & 0.55 & 0.96 \\
\hline 121.49 & 1.93 & 0.0159067 & 1.04 & 0.89 & 1.93 \\
\hline 166.00 & 3.17 & 0.0190857 & 1.95 & 1.22 & 3.17 \\
\hline
\end{tabular}

Step-Drawdown Tests

gpm $=$ Gallons per minute

$\mathrm{ft}=$ Feet

$\mathrm{S}_{\mathrm{w}}=$ Drawdown

\subsection{Effects of Temperature Profile Changes}

Formation pressure is commonly monitored with a pressure transducer located near the water surface rather than in the completion interval for practical reasons. The water surface elevation reflects the formation pressure as a function of the water density in the water column. The water-column density may vary as a result of temperature and water quality variation. When the density profile is constant, the water-surface elevation varies linearly, with respect to the formation pressure after accounting for secondary components of the responses, such as barometric 
pressure variation and earth tides. However, pumping the well can alter the temperature profile as a result of moving water from the completion interval to the surface replacing both water in the water column below the pump intake and conduction of heat above the pump intake. After pumping has begun, the temperature profile will approach a new equilibrium. After pumping ceases, the profile will equilibrate back to the ambient profile. The volume expansion (or contraction) as temperatures increase (or decrease) affects the water-surface elevation independent of the formation pressure changes, and the effect can be significant due to large temperature changes and/or long water-column length. Borehole temperature profiles were logged intermittently during development, both during ambient conditions and at multiple pumping rates and then again following recovery and the testing program.

Water quality variation affecting the water-column density may result from suspended sediment in the water column and/or gas entrainment in the water, due to air removal from the formation from drilling production and to exsolving gas from depressurizing the water. However, no information was collected to provide understanding of these factors, and they are assumed to have a negligible effect.

Density variation that occurs in the water column above the PXD does not effect the pressure measurement. If formation pressure were measured at the completion interval, changes in water-column density would not affect measurement of formation pressure changes.

\subsubsection{Temperature Profile Variation}

Figure 3-2 shows a selection of overlayed temperature logs to display the transient differences. The legend provides the logging run identification and indicates the well pumping rate for each log. A predevelopment equilibrium temperature profile was not logged. The post-recovery log best represents an ambient equilibrium $\log$ and would represent a starting profile for changes resulting from pumping. This log was run eight days after pumping ceased. The actual ambient temperature near the water surface is approximately 93.4 degrees Fahrenheit $\left({ }^{\circ} \mathrm{F}\right)$ (determined from PXD monitoring prior to any pumping). The post-recovery temperature $\log$ shows temperatures about $0.6^{\circ} \mathrm{F}$ above ambient in the upper $100 \mathrm{ft}$ of the water column at the time of logging, indicating that the temperature in the well was still equilibrating. The other two nonpumping logs are similar but represent intermediate stages of equilibration to ambient, because they were run shortly after pumping had ceased. Temperature data from several sources are used in this analysis. Each instrument is factory calibrated and field calibrated except for the PXD temperature measurement. However, the PXD temperature data is consistent with the surface measurements of temperature from the in-line water quality instrument, suggesting that it is fairly accurate.

The pumping temperature logs are presented in the relevant time sequence they were run. During pumping, the temperature profile changes approximately $2,740 \mathrm{ft}$ bgs; during pumping below this depth, the profile is the same as the ambient profile. Evaluation of the flow logs (Section 3.5.4) indicates that there was no production below this depth. The pumping temperature profile is almost 
identical for all three pumping rates, and the pattern of temperature change above $2,740 \mathrm{ft}$ bgs corresponds closely to the production profile. Above 2,300 $\mathrm{ft}$ bgs, the temperature is constant at about $95.4^{\circ} \mathrm{F}$ during pumping corresponding to the top of the production interval. The relationship of the temperature profile change to the production profile is discussed in Section 3.5.2. The ambient temperature profile of this well below $2,350 \mathrm{ft}$ bgs is reversed from the normal geothermal gradient: temperature decreases with depth. This temperature profile is consistent for all the temperature logs; however, the reason for the reversed gradient is not known.

The equilibration process in the upper part of the completion interval above $2,200 \mathrm{ft}$ bgs is affected by reinjection of hot water from the production tubing and by dissipation of residual heat from the pump. Note that there was no check valve installed in this well during testing due to difficulties encountered in trying to install the check valve. The water temperature produced at the surface was about $98.8^{\circ} \mathrm{F}$ (equilibrated PXD temperature ranging from approximately 97.9 to $99.6^{\circ} \mathrm{F}$ on the Hydrolab ${ }^{\circledR}$ monitoring), which is several degrees warmer than the stabilized temperature above the production interval $\left(95.4^{\circ} \mathrm{F}\right)$ indicated on the temperature $\log$. The difference is heat added to the water by pumping. There are several temperature $\log$ features related to physical features of the downhole equipment. The temperature profile is affected as the logging tool emerges at $2,018 \mathrm{ft} \mathrm{bgs}$ from the access line through which it is run, and the temperature increase above $1,900 \mathrm{ft}$ bgs in the post-recovery log is probably due to residual heat from the reinjection of water in the production tubing at pump shutdown, which primarily rebounds upward into the main casing.

\subsubsection{Effect of Temperature Profile Change on Measured Water-Level Response}

With regard to the analysis of the formation pressure response to well production, the effect of water column expansion due to the temperature profile change on the measured water-level response must be considered if it is substantial. Figure 3-3 shows an overlay of the synthetic ambient and synthetic equilibrium pumping temperature profiles constructed according to the analysis of temperature variation presented in the previous section. The ambient and pumping temperature profiles cross at about $2,150 \mathrm{ft}$ bgs, a short distance above the production interval. Above this point the shift from the ambient to the pumping profile is an increase in temperature, with expansion of the water column. Below this point to the bottom of the production interval at about $2,740 \mathrm{ft}$ bgs, the shift is a decrease in temperature with contraction of the water column.

Data for temperature versus density from the CRC Handbook of Chemistry and Physics, 81st Edition, p. 6-3 (CRC Press, 2000) were used to develop formulas for calculating the density dependence on temperature for the range of temperature observed. For convenience, the water density conversion factor is presented in terms of the water column height per unit pressure. The formulas are:

Conversion Factor (degrees Celsium $\left.\left[{ }^{\circ} \mathrm{C}\right]\right) \mathrm{ft} / \mathrm{psi}=$ $\left(0.000000026 *\left[{ }^{\circ} \mathrm{C}\right]^{3}\right)+\left(0.000012258 *\left[{ }^{\circ} \mathrm{C}\right]^{2}\right)-\left(0.000034252 *\left[{ }^{\circ} \mathrm{C}\right]\right)+2.305396395$ 
Conversion Factor $\left(\left[{ }^{\circ} \mathrm{F}\right]\right) \mathrm{ft} / \mathrm{psi}=\left(0.000000004 *\left[{ }^{\circ} \mathrm{F}\right]^{3}\right)+\left(0.000004203 *\left[{ }^{\circ} \mathrm{F}\right]^{2}\right)$ $-\left(0.000236545^{*}\left[{ }^{\circ} \mathrm{F}\right]\right)+2.308804990$

Water expansion was evaluated using numerical integration of the incremental expansion for the temperature difference between the two synthetic temperature logs. The above formulas were used to calculate the expansion as the inverse of the density change. The expansion from the top of the production interval to the water surface from the start of the constant-rate test to the point of temperature equilibration was about $0.15 \mathrm{ft}$. Temperature changes in the production interval were not included because the effect of the temperature changes in this interval directly affect the head gradient driving flow into the well, and are reflected in the actual drawdown response. The calculated temperature expansion represents the maximum amount that the drawdown during pumping, as recorded by the PXD near the water surface, is reduced by the water column expansion. This amount of expansion is about 12.5 percent of the maximum observed aquifer drawdown. Because $T$ is directly proportional to the aquifer drawdown, the effect of the temperature expansion results in underestimation of the $T$ by about 12.5 percent. This analysis indicates the potential importance of correcting for the temperature expansion.

Because the temperature profile change takes a significant length of time to reach equilibrium, the associated expansion also occurs progressively. An approximate surrogate for progressive change in the temperature profile is the PXD temperature record during pumping, which records the change at one depth near the water surface. The temperature change process at this depth is thought to be the slowest in the system. This record shows that temperature equilibration took about 6.6 days after the start of pumping. The temperature profile change with time is not defined with intermediate temperature logs, so an accurate continuous correction for the drawdown response could not be calculated; therefore, the hydraulic testing data (as analyzed in Section 3.4) are not corrected for temperature effects. The uncertainty associated with the temperature expansion should be kept in mind with respect to the result of the hydraulic analysis.

\subsection{Pumping-Test Analysis}

The hydraulic testing of the well is analyzed under ambient and transient conditions to provide both the composite and discrete-interval hydraulic properties of the ER-6-2 LCA completion. The analyses are based on interpretation of a 10-day constant-rate pumping test and on spinner-tool flow logging. The following sections describe the method, conceptual model, analysis, and results for the ER-6-2 single-well pumping test drawdown and recovery responses. Section 3.5 follows with the interpretation and analysis of measured discrete production from flow logging. 


\subsubsection{Method of Analysis}

The analysis of pressure/head transient data begins by reviewing the data with the $\log$-log pressure and pressure derivative diagnostic plot to identify characteristic responses of certain types of flow regimes and to identify how changes through time refine conceptual understanding (Horne, 1995). For instance, in the pumping well, the wellbore storage period has a unit slope, and having identified the end of the wellbore storage period, infinite-acting radial flow could be expected within $1.5 \log$ cycles. If a constant rate of drawdown (e.g., Theis-like conditions) does not occur, then another conceptual model must be considered.

The well-test interpretation program nSights (n-Dimensional Statistical Inverse Graphical Hydraulic Test Simulator) was used to estimate the formation properties. The nSights program was developed by INTERA for Sandia National Laboratories based on the well-test analysis code GTFM (Graph Theoretic Field Model), the precursor to nSights. Field use for GTFM has a long history including the Swiss, Swedish, and French nuclear waste programs, as well as at the DOE Waste Isolation Pilot Plant in New Mexico (Roberts et al. 1999). A description of the governing equations used in both codes is found in Pickens et al. (1987). Following Sandia National Laboratories Nuclear Waste Management Program Procedure NP19-1, "Software Requirements," Rev. 4, nSights was verified to meet NQA-2 requirements (ASME, 1990). Verification was documented through comparison to the analytical solutions for constant-rate pumping tests (Theis, 1935), constant drawdown tests (Lohman, 1972), slug tests (Cooper et al., 1967), and pulse tests (Bredehoeft and Papadopulos, 1980). The nSights program is complete with a suite of statistical routines that support the identification and quantification of parameter sensitivity and uncertainty.

The nSights program uses a numerical approach to simulate radial/nonradial groundwater flow through a confined, single-phase, single-porosity, one-dimensional (for this analysis) flow domain in response to boundary conditions (i.e., pumping rate changes) applied at the production well. The flow domain is discretized into a system of concentric rings centered on the borehole that uses a multiplicative factor to increase the spacing between rings with increasing distance from the borehole. Each ring is represented by a node, hence the radial symmetry.

The formation thickness used for analysis is $1,069 \mathrm{ft}$, the thickness of carbonate formation (all considered part of the LCA) from the static water level at 1,785 ft bgs to the top of the Chainman Shale at 2,883 ft bgs, less a 29-ft interbedded stratum of quartzite (see Figure 1-3). The thickness was defined to determine the average hydraulic properties for the LCA as a carbonate formation.

\subsubsection{Conceptual Model}

The interpretive conceptual model is determined by reviewing the log-log diagnostic plots of the drawdown data (Figure 3-4). After diagnosing the conceptual model from the log-log analysis, the formation properties associated with the conceptual model (e.g., transmissivity and storativity for a homogenous 
infinite system) are adjusted to fit the measured response data. Inferring the proper conceptual model and formation hydraulic parameters from measured data is an inverse problem. Inherent to any inverse problem is a degree of uncertainty, in both the interpretive model and its associated parameters, that results from the combined effect of nonideality in the real geologic system and parameter correlation (nonuniqueness). Considering this, a response indicative of a heterogeneous formation needs to be qualitatively interpreted in the context of the geologic model in order to have confidence in the parameters estimated. Additional confidence is gained in the estimated properties if the entire test sequence (i.e., drawdown and recovery to static) is also fit by a consistent set of estimated parameters.

Because it is the slope of the head change $(d H)$ with time from which the diagnosis is made, the derivative $(d H / d \ln t)$ aids in the identification of flow regimes. Within the first 0.004 days (six minutes) from the start of pumping, a slope of 1.0 is identified in both the head change and derivative, indicative of the wellbore storage period. Directly following is the characteristic 1.5-log cycle period during which the pressure response undergoes a transition between wellbore and formation response (Horne, 1995). At 0.2 days from the start of pumping, the derivative slope begins to flatten to a zero slope, indicative of a radial flow period, and endures to 1.0 day. Just after day 1.0, the (value of, not the slope of the) derivative goes to 0.0 as the head change approaches a constant value. This response may indicate a radial, steady-state flow period. Although in theory steady-state flow is impossible in a confined aquifer, a cessation in drawdown indicates that the pumping rate is not sufficient to overcome the background hydraulic gradient during this period.

A second permissible conceptual model is that a constant-head boundary was reached as the derivative value begins to drop to 0.0 , which may result in steady-state flow. Such a boundary was identified in the ER-7-1 single-well test of the Yucca Flat LCA (SNJV, 2004) and was interpreted as a CAU-scale, high permeability, fault-related feature with (bi)linear flow geometry (SNJV, 2005c). Historical hydraulic testing of the LCA at the NTS has shown that fracture-dominated flow systems are prevalent (e.g., Garber and Thordarson [1962], Rojstaczer [1987], Laczniak et al. [1996], Belcher et al., [2001]). Therefore, it is permissible that the steady-state flow observed from the ER-6-2 response is related to high permeability fracture- or fault-related features that are apparent as a constant-head boundary at the relatively low pumping rate (166 gpm) applied. It is worthy to note that ER-6-2 is approximately 3,000 ft east of the Topgallant Fault at ground surface. The Topgallant is possibly a high transmissivity zone along the direction of fault continuity (SNJV, 2005c).

From interpretation of the log-log diagnostics alone, both the radial-to-steady-state model and the fault-related constant-head boundary conceptual model are permissible. To address this ambiguity, inverse modeling of the hydraulic response can provide insight as to which conceptualization is more credible. After 3.5 days of pumping, the rate declines and formation head immediately begins to recover. The recovery results in an inflection point in the head change diagnostic, masking further identification of the steady-state response. The inflection point also results in the derivative value dropping to 0.0 ; therefore, differentiation 
between the steady-state response and head recovery becomes convoluted and uninterpretable after 3.5 days.

\subsubsection{Hydraulic Response Analysis}

The nSights numerical well-test simulator was used to analyze the test data. nSights does not use the typical analytic solution approach where a mathematical model constructed from a prototypical geologic geometry is selected and then formation properties determined. It uses a more general formulation known as the flow dimension, where the geometry factor can be varied. The geometry factor, or flow dimension, is related to the power by which the area contributing to flow changes with distance into the formation from the borehole (Barker, 1988).

Integer flow dimensions of 1,2 , and 3 are respectively equivalent to linear, radial, and spherical flow. Walker and Roberts (1998) show that the flow dimension can be calculated as

where:

$$
n=2-2 v ; v=\lim _{t \rightarrow \infty} \frac{d}{d(\log t)}[\log (d H / d \ln t)]
$$

$v=$ Late-time slope of the pressure derivative

$n=$ Flow dimension

Thus, linear flow with a slope of 0.5 has a flow dimension of 1.0 , and radial flow with a slope of 0.0 has a flow dimension of 2.0. For one-dimensional simulations applied in this analysis, the flow dimension may be conceptualized as the numerical analogue to the actual heterogeneity that exists within the formation volume tested, and is analogous to the geometric configuration of a heterogeneous permeability field that would be parameterized in a two- or three-dimensional numerical model.

nSights performs nonlinear regression to define a set of formation hydraulic parameters that provide a best-fit simulated response to the measured data. Hydraulic conductivity $(K)$, specific storage $\left(S_{\mathrm{s}}\right)$, and flow dimension $(n)$ are defined as the fitting parameters. Optimization of the flow dimension, in conjunction with an uncertainty (perturbation) analysis, provides insight as to which of the above conceptual models is supported by the data. The flow regime beyond 1.0 day from the start of pumping may or may not be radial depending on whether the drop in the head derivative to a value of zero is the result of steady-state radial flow or flow from a constant-head boundary (possibly related to a fault or fractured feature).

Explicit time sequences of the ER-6-2 hydraulic response data were selected as the measured response for the fitting period. The remainder of the data are uncertain for reasons described in the paragraph below and are defined consequently as fixed or known head response periods used to constrain the simulated response. The entire response is partitioned into four sequences (see Figure 3-5). Static conditions prior to the pump test are defined as a nonpumping flow period (F_01). This period simply defines the ambient, static condition. The first 3.5 days from 
the start of pumping is defined as a pumping flow period (F_02), and is also assigned as the first portion of the fitting period. Following 3.5 days from pumping, head recovered in the well. The recovery corresponds to a continuous decrease in the pumping rate (Figure 3-5). The period from 3.5 days to the end of pumping is defined within a fixed head sequence (H_01) used to constrain the simulated head response. Why this period was not included as part of the fitting period is discussed below. Sequence H_01 also extends into the early-time pump shut-down period when the absence of a check valve results in borehole surging above static, thereby introducing an unquantifiable impact on the measured pressure response. The remainder of the formation recovery period is defined as a nonpumping flow period (F_03) and also as the second portion of the fitting period. Parameter estimates are dependent on the fit to sequences F_02 and F_03, which bound the entire ER-6-2 response period from the start of pumping to the final recovery measurement.

Sequence H_01 is defined as a constraining, fixed-head sequence because the response data are uncertain. During the pumping period, head begins to recover at 3.5 days from pumping, coincidental with the start of a monotonically decreasing pumping rate. Although nSights implements the rate change as a time-varying boundary condition at the well, the magnitude of measured head recovery is too great for the less-than-10-gpm rate decrease over the final six days of pumping. The recovery may be partially attributed to transient well development effects. A similar mid-pumping recovery occurred in the ER-6-1\#2 single-well response, without rate fluctuations, that can be attributed only to transient development (skin) effects (SNJV, 2005c) or equipment issues. ER-6-1\#2 is completed in the LCA, 4.9 miles to the northeast of ER-6-2. Upon the end of pumping, the early-time portion of recovery is uncertain because of an immediate head recovery above static, that undergoes drawdown, resulting from the absence of a check valve in the downhole test equipment.

\subsubsection{Best-Fit Parameter Estimates and Uncertainty}

Formation parameter estimates derived from simulation of the fitting response period are subject to uncertainty from three primary sources: error in measured data (accuracy and precision), error in the conceptual model and subsequent statement/setup of the problem, and parameter correlation. The first is straightforward; data error translates into parameter estimate error, which is why sequence $\mathrm{H} \_01$ is not incorporated as a fitting parameter. Regarding the conceptual model and problem setup, we assume that development of the conceptual model from the log-log plot diagnosis is certain through the first 1.0 day of pumping. The flow dimension fitting parameter will be used to assist in determining whether the steady-state radial flow or constant-head boundary conceptual model is better supported by the data. Regarding parameter correlation, it is the covarying relationship between parameters that, in many cases, permits multiple parameter combinations to provide equivalent fits to the data. A perturbation analysis is applied to check parameter correlation (colinearity) as defined by the correlation-covariance matrix (Table 3-3), and to 
ensure that the best-fit parameter set does not reside in a local minima on the objective function $\left(\chi^{2}\right)$ surface.

The best-fit results from a 1,000-simulation perturbation analysis are presented in Figure 3-5 (top). Each fit in the diagram corresponds to the global minimum region on the three-parameter objective function surface. Because the parameter estimation is $\chi^{2}$-minimization, the associated parameters provide the best statistical fit (and hence most plausible answers) to the data. The corresponding parameters are presented in Figure 3-6 $\left(K-S_{\mathrm{s}}\right)$ and Figure 3-7 $(K-n)$. Those deemed as the best-fit subset are listed in Table 3-2.

Table 3-2

Best-Fit Hydraulic Parameters

\begin{tabular}{|c|c|c|c|c|c|}
\hline \multicolumn{2}{|c|}{$K^{\mathbf{1}}$ (ft/d) } & \multicolumn{2}{c|}{$n^{\mathbf{1}(-)}$} & \multicolumn{2}{c|}{$S_{\mathbf{s}}^{1,2}(\mathbf{1} / \mathrm{ft})$} \\
\hline \hline minimum & maximum & minimum & maximum & minimum & maximum \\
\hline 120 & 290 & 1.83 & 1.85 & $2 \times 10^{-9}$ & $2 \times 10^{-6}$ \\
\hline
\end{tabular}

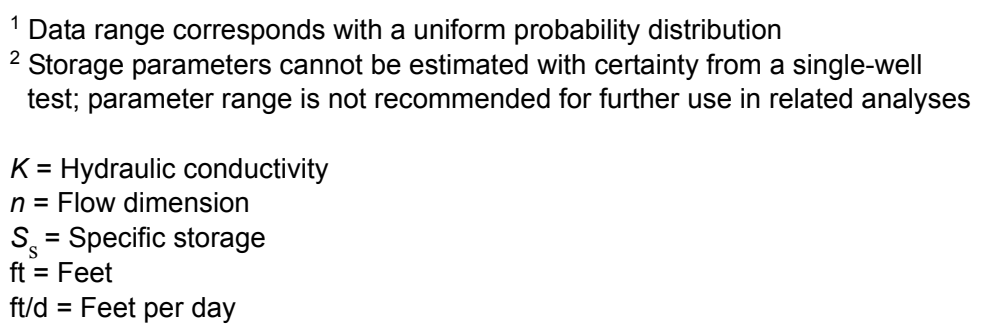

Hydraulic conductivity $(K)$ is reasonably constrained between 120 and 290 feet per day ( $\mathrm{ft} / \mathrm{d})$. The upper and lower $K$ bounds are controlled by the specific storage $\left(S_{\mathrm{s}}\right)$ parameter, which in the case of a single-well test cannot be determined with any accuracy. The fitting parameter covariance-correlation table for the lowest objective function fit is presented in Table 3-3. The correlation between $K$ and $S_{\mathrm{s}}$ is -0.28 ; a narrow range of $K$ corresponds with a several order-of-magnitude range of $S_{\mathrm{s}}$. $K$ remains reasonably constrained within a range of less than $200 \mathrm{ft} / \mathrm{d}$. However, the (scaled) variance for $K$ (Table 3-3) indicates that the objective function has little sensitivity to this parameter, decreasing the likelihood that it is properly characterized by the measured data (Yeh, 1986). Parameter variance is inversely related to the objective functions sensitivity to that parameter, where sensitivity is characterized by the Jacobian (Press et al., 1992). During parameter optimization and calculation of the Jacobian, nSights scales the fitting parameters to values between 0 and 1 ; therefore, the maximum theoretical parameter variance $\left(8.33 \times 10^{-2}\right)$ (Harr, 1987) from the scaled data, also referred to as the scaled variance, would correspond to that of a uniform distribution with a range from 0 to 1 , equivalent to the case where all optimized parameter values are equiprobable in this range. The large variance for both $K$ and $S_{\mathrm{s}}$, well above the maximum theoretical variance, indicates that the model is over-parameterized; $K$ and $S_{\text {s }}$ cannot be simultaneously uniquely identified (Figure 3-6). 
Table 3-3

Parameter Covariance - Correlation (bold text) Matrix

\begin{tabular}{|c|c|c|c|}
\cline { 2 - 4 } \multicolumn{1}{c|}{} & $\boldsymbol{K}$ & $\boldsymbol{n}$ & $\boldsymbol{S}_{\mathbf{s}}$ \\
\hline$K$ & 7.56 & -0.26 & $-3.71 \times 10^{1}$ \\
\hline$n$ & $-\mathbf{0 . 8 3}$ & $9.22 \times 10^{-3}$ & 1.28 \\
\hline$S_{\mathrm{S}}$ & $\mathbf{- 0 . 2 8}$ & $-\mathbf{0 . 0 1}$ & $1.83 \times 10^{2}$ \\
\hline
\end{tabular}

$$
\begin{aligned}
& K=\text { Hydraulic conductivity } \\
& n=\text { Flow dimension } \\
& S_{\mathrm{S}}=\text { Specific storage }
\end{aligned}
$$

Hydraulic conductivity is better correlated with the flow dimension $(n)$ parameter (Figure 3-7 and Table 3-3), which itself is better constrained by the data. Over the same range in $K, n$ is bounded between 1.83 and 1.85 , values just under that representing radial flow. Because of the good constraint in the flow dimension that is imparted by the measured data, a slightly sub-radial flow regime is interpreted that supports the near-radial-to-steady-state flow conceptual model and insubstantiates a more linear fracture-flow dominated system. It is also conceptually appropriate that the flow dimension is less than two; multiple borehole intervals of discrete flow are identified during flow logging (Section 3.4.2), which are representative of flowing apertures or small fractures. However, over the complete 1,069-ft thickness of the LCA tested, the formation effectively responds like a porous medium with (sub-)radial flow.

As a practical demonstration of the sensitivity of $K$ to the flow dimension parameter, the Cooper-Jacob (1946) method is used to estimate formation transmissivity from ER-6-2 drawdown corresponding to the radial flow period. From the log-log diagnostic (Figure 3-4), the zero-slope period of the head derivative (indicating infinite-acting radial flow) is between 0.2 and 1.0 day from pumping. As stated, this period is before the flow regime representative of steady-state flow. Figure 3-8 illustrates the straight-line fit to the drawdown for the radial flow period. Applying a 1,069-ft formation thickness, the formation hydraulic conductivity is $34 \mathrm{ft} / \mathrm{d}$. This result is one order of magnitude below the range identified using nSights. However, nSights simulations in which $K$ and $S_{\mathrm{s}}$ were optimized parameters while $n$ was held constant at 2.0 resulted in $K$ estimates nearly identical to that derived from the Cooper-Jacob analysis. The simulated best fits were significantly worse and considered unacceptable. Therefore, inclusion of the flow dimension parameter $n$ appears to honor an actual flow geometry that is slightly sub-radial, presumably from sparse fracturing. The sub-radial component may not be visually identifiable from the log-log diagnostic because of noise in the measured data.

Further corroboration is supplied by the sensitivity of the response fit to $n$, reflected in the low variance (Table 3-3) relative to the maximum theoretical variance of $8.33 \times 10^{-2}$. This indicates that the best-fit $(n)$ parameters are tightly clustered about its mean. Additionally, Figure 3-9 shows the objective function sensitivity through time to all three fitting parameters. That the simulated fit is 
more sensitive to $n$ than to both $K$ and $S_{\mathrm{s}}$ indicates that the ER-6-2 response contains information describing properties of the formation beyond hydraulic conductivity and storage. The greater the sensitivity of a parameter, the greater the likelihood that it is properly characterized on the basis of the data available (Yeh, 1986). Conceptually, the flow geometry is the most influential formation property beyond conductivity and storage that affects the hydraulic response. It should be noted, however, that flow geometry does not have to strictly conform to the conceptual model presented; other components, representative of any plausible form of heterogeneity that affected the hydraulic response, are implicit in the flow geometry parameter estimated.

Finally, it should be noted that both double-porosity models and single-porosity models with well skin parameters were not able to fit the measured data, using a variety of different fitting sequences, better than the model presented above.

\subsection{Interpretation and Analysis of Measured Discrete Production}

Discrete flow in the well as a function of depth was recorded using a spinner flowmeter (SFM) during periods of constant-rate pumping at different pumping rates. The flowmeter impeller spins in response to water moving through the meter. The rate of revolution is related to water velocity past the impeller, and the instantaneous flow rate is calculated in an equation that accounts for wellbore diameter and the SFM trolling speed. The coefficients of the equation relating the impeller response to the discharge are first determined by calibration in a calibration facility. However, in the field, the SFM response is influenced by a large number of factors specific to the individual well. These factors are: pumping rate variation, flow variability due to hole condition, centralization of the impeller meter, impeller efficiency due to condition of the blades and bearings, water temperature, entrained air, and sediment load. Therefore, it is necessary to adjust the basic calibration based on field performance. A calibration can be performed in the well using SFM data collected in blank casing above the slotted interval where the SFM response can be directly compared to the measured surface discharge; however, the configuration of this well did not permit calibration of the SFM tool. Hence, the calibration will be derived during analysis from the flow logs.

\subsubsection{Flow Logging During Pumping}

During pumping the spinner tool was run between 2,030 and 3,375 $\mathrm{ft}$ bgs at line speeds of 20, 40 and $60 \mathrm{fpm}$ in both upward and downward directions. Stationary (nontrolling) depth specific logs were also run under pumping conditions.

Table 3-4 lists the trolling logs run at the various line-speed rates and the depth ranges for each log.

All logs were run through the entire extent of the accessible interval, 2,030 $3,375 \mathrm{ft}$ bgs. However, the open borehole extended above 2,030 to 1,746 ft bgs. This section of the open borehole was inaccessible to logging because the pump 
Table 3-4

Listing of Trolling Flow Logs

\begin{tabular}{|c|c|c|c|c|c|}
\hline Run Number & Date & $\begin{array}{l}\text { Direction } \\
\text { of Run }\end{array}$ & $\begin{array}{c}\text { Targeted } \\
\text { Line Speed } \\
(\text { fpm) }\end{array}$ & $\begin{array}{c}\text { Surface } \\
\text { Discharge } \\
\text { (gpm) }\end{array}$ & $\begin{array}{l}\text { Start - Finish } \\
\text { (ft bgs) }\end{array}$ \\
\hline er62mov07a & \multirow{12}{*}{$7 / 19 / 2004$} & Down & 20 & 75 & $2,030-3,375$ \\
\hline er62mov08a & & Up & 20 & 75 & $3,375-2,030$ \\
\hline er62mov09a & & Down & 40 & 75 & $2,030-3,375$ \\
\hline er62mov10a & & Up & 40 & 75 & $3,375-2,030$ \\
\hline er62mov11a & & Down & 60 & 75 & $2,030-3,375$ \\
\hline er62mov12a & & Up & 60 & 75 & $3,375-2,030$ \\
\hline er62mo13a & & Down & 20 & 120 & $2,030-3,375$ \\
\hline er62mov14a & & Up & 20 & 120 & $3,375-2,030$ \\
\hline er62mov15a & & Down & 40 & 120 & $2,030-3,375$ \\
\hline er62mov16a & & Up & 40 & 120 & $3,375-2,030$ \\
\hline er62mov17a & & Down & 60 & 120 & $2,030-3,375$ \\
\hline er62mov18a & & Up & 60 & 120 & $3,375-2,030$ \\
\hline er62mov19a & \multirow{6}{*}{$7 / 20 / 2004$} & Down & 20 & 165 & $2,030-3,375$ \\
\hline er62mov20a & & Up & 20 & 165 & $3,375-2,030$ \\
\hline er62mov21a & & Down & 40 & 165 & $2,030-3,375$ \\
\hline er62mov22a & & Up & 40 & 165 & $3,375-2,030$ \\
\hline er62mov23a & & Down & 60 & 165 & $2,030-3,375$ \\
\hline er62mov24a & & Up & 60 & 165 & $3,375-2,030$ \\
\hline
\end{tabular}

fpm - Feet per minute

$\mathrm{ft}$ bgs - Feet below ground surface

gpm - Gallons per minute

was installed to a depth of $1,952 \mathrm{ft}$ bgs, and the access line hung to $2,017 \mathrm{ft}$ bgs. Flow logs were run at line speeds of 20, 40, and $60 \mathrm{fpm}$ both downward and upward. The multiple runs are used in a calibration process. Desert Research Institute typically provides calibrated data at $0.2 \mathrm{ft}$ resolution; however, this calibrated data was not available at the time of this analysis. A description of the calibration, methods, and raw data manipulation, through the conversion of the measured spinner rate (revolutions per second) to interval flow rates, is reported by DRI (Oberlander and Russell, 2003).

Comparison of the maximum measured downhole flow rate to the surface measured production rate indicates that all the surface production is accounted for through the logged depth interval. Similarly, the flow logs did not quite go to total depth of the well, but the logs clearly indicate that there was no production in the lowermost interval that was logged. Consequently, the flow logs are interpreted to provide complete information on the production throughout the complete well completion interval. 


\subsubsection{Flow Profiles During Pumping}

To evaluate flow profiles during pumping, log runs at $40 \mathrm{fpm}$ logging rate in the up direction were selected as the most representative and consistent. The logs are shown on Figure 3-10. The logs were normalized, dividing the measured downhole flow rates by the average surface flow rate, to put them onto a common flow rate scale so that the differences could be readily evaluated. These logs overlay closely, and there is no substantial difference between the logs for different pumping rates. Much of the inflow to the borehole during pumping is characterized by large increases (almost step increases) over short vertical intervals. Such increases occur in intervals from 2,740-2,718, 2,522-2,496, and 2,328-2,324 ft bgs. More gradual, linear increases occur over the intervals 2,718-2,522 and 2,496-2,300 ft bgs. The total interval of inflow is from about 2,740-2,300 ft bgs, which corresponds to the same interval where the temperature profile changed during pumping. This is illustrated in Figure 3-11, which shows both the production flow log and the temperature logs for ambient flow and 165 gpm production.

A linearized flow log was defined based on the 165 gpm flow log that identifies different flow intervals (interval top and bottom) by character of the production and assigns the proportion of production for each. This is illustrated in Figure 3-12 and tabulated in Table 3-5. The flow fraction is the proportion of total

Table 3-5

Linearized Flow Log for 165 gpm

\begin{tabular}{|c|c|c|c|}
\hline $\begin{array}{c}\text { Depth Interval } \\
\text { (ft bgs) }\end{array}$ & $\begin{array}{c}\text { Normalized } \\
\text { Flow - Top of } \\
\text { Interval }\end{array}$ & Flow Fraction & $\begin{array}{c}\text { Interval Length } \\
\text { (ft) }\end{array}$ \\
\hline \hline $2031-2305$ & 1.00 & 0.00 & 274 \\
\hline $2305-2338$ & 1.00 & 0.18 & 33 \\
\hline $2338-2388$ & 0.82 & 0.11 & 50 \\
\hline $2388-2480$ & 0.71 & 0.07 & 92 \\
\hline $2480-2532$ & 0.64 & 0.34 & 52 \\
\hline $2532-2579$ & 0.30 & 0.02 & 47 \\
\hline $2579-2718$ & 0.28 & 0.00 & 139 \\
\hline $2718-2733$ & 0.28 & 0.28 & 15 \\
\hline $2733-3375$ & 0.00 & 0.00 & 641 \\
\hline
\end{tabular}

$\mathrm{ft}=$ Feet

bgs $=$ Below ground surface

flow that originated in the interval. The total depth interval covered by the normalized log corresponds to the depth range of the flow logs. Production in the LCA is almost entirely through fracture flow, and the hydraulic conductivity of any section of the through-flow in fractures, and the hydraulic conductivity of any section of formation is related to the intensity and characteristics of the fracturing. The step increases of flow over short intervals indicate localized, more conductive 
fractures or fractured zones as compared to the fracturing across the rest of the formation.

\subsubsection{Normalized Transmissivity Calculation}

The SFM data provide an assessment of production from sections of the open completion interval at fine spatial resolution. The interval production can be used for the determination of the hydraulic conductivity of discrete intervals within the entire length of the composite producing interval, which in turn allows direct comparison of the hydraulic conductivity of the different flow intervals identified using flow logging information (Table 3-5). When compared with the spatial interpretation of wellbore geology and other information such as fracture logs, when available, interval hydraulic conductivities can be used to distinguish the features of the formation that are the primary sources of production. The interval results are based on the composite formation hydraulic conductivity estimate derived from the constant-rate test analysis (Section 3.4.3) using the normalized transmissivity calculation method.

The normalized transmissivity calculation method used in interpreting SFM results assumes the analyst has an estimate of the borehole interval transmissivity for the entire interval analyzed with the fluid logs. Based upon knowledge of the total logged-section transmissivity $(T)$, one can estimate the transmissivity $\left(T_{\mathrm{i}}\right)$ for each borehole interval. This method takes advantage of the fact that flow becomes horizontal at the well-bore radius $\left(r_{\mathrm{w}}\right)$ in an ideally layered aquifer even when the individual layers have relatively high contrasts in conductance (Javendel and Witherspoon, 1969). When this condition is met, the flow from an individual inflow point or layer is proportional to that layer's transmissivity by a proportionality constant (Molz et al., 1989). The relationship for a layer's transmissivity can be expressed as

$$
q_{i}=\alpha T_{i}
$$

where $q_{i}$ is the flow rate from the layer $i$, and $\alpha$ is the proportionality constant. Molz et al. (1989) report that Equation 3-5 is applicable at dimensionless times greater than 100 , where dimensionless time is:

$$
\frac{4 t T_{i}}{S_{i} r_{w^{2}}} \geq 100
$$

The proportionality constant $\alpha$ is equal to

$$
\alpha=Q_{w} / T
$$

where $Q_{w}$ is the total production rate for the logged interval. With the total production rate known, and an estimate of $q_{i}$ for each layer from fluid logging, one can calculate a normalized transmissivity equal to

$$
\frac{T_{i}}{T}=\frac{q_{i}}{Q_{w}}
$$


where $(1.0 \geq T / T>0)$. The vertical transmissivity distribution can be presented as a normalized distribution. In this case, no assumptions are made about $S, S_{\mathrm{i}}$, $t$, or $r_{w}$. If one has a good estimate of $T$, then the individual transmissivities $\left(T_{i}\right)$ can be calculated as dimensional quantities. If $T$ can be estimated from a steady-state response, estimates of $S, S_{\mathrm{i}}$, and $t$ are not required. Systematic or multiplicative errors will be canceled out using a normalized transmissivity interpretation method.

\subsubsection{Interval Hydraulic Conductivities}

Table 3-6 shows the results using the normalized transmissivity method to calculate interval hydraulic conductivities. The first four columns of the table, taken from Table 3-5, present the normalized flow log for the 165 gpm production rate. In Table 3-2, the results of the constant-rate test analysis were presented as the minimum $(120 \mathrm{ft} / \mathrm{d})$ and maximum $(290 \mathrm{ft} / \mathrm{d})$ for a uniform distribution of $K$, based on a formation thickness of $1,069 \mathrm{ft}$, with a mean $K$ of $205 \mathrm{ft} / \mathrm{d}$. This was used in the normalized transmissivity calculation by calculating a mean $T$ for the uniform distribution, 219,145 square feet per day $\left(\mathrm{ft}^{2} / \mathrm{d}\right)$. The interval $T$ was calculated as described in Section 3.5.3, and the interval $K$ was then calculated by dividing the interval $T$ by the interval thickness. Values are provided for the mean value as well as the minimum and maximum (in parentheses). These results further emphasize the wide variation in productivity of different intervals of the formation.

Table 3-6

Interval Hydraulic Conductivities

\begin{tabular}{||c|c|c|c|c|c||}
\hline $\begin{array}{c}\text { Depth Interval ft } \\
\text { bgs }\end{array}$ & $\begin{array}{c}\text { Normalized } \\
\text { Flow - Top of } \\
\text { Interval }\end{array}$ & $\begin{array}{c}\text { Flow } \\
\text { Fraction }\end{array}$ & $\begin{array}{c}\text { Interval } \\
\text { Length } \\
\text { (ft) }\end{array}$ & $\begin{array}{c}\text { Interval } \boldsymbol{T}^{1} \\
\left.\text { (ft }{ }^{2} / \mathbf{d}\right)\end{array}$ & $\begin{array}{c}\text { Interval } \boldsymbol{K}^{\mathbf{1}} \\
\text { (ft/d) }\end{array}$ \\
\hline \hline $2031-2305$ & 1.00 & 0.00 & 274 & 0 & $\mathrm{~N} / \mathrm{A}$ \\
\hline $2305-2338$ & 1.00 & 0.18 & 33 & $39,446(23,090-55,802)$ & $1,164(681-1,646)$ \\
\hline $2338-2388$ & 0.82 & 0.11 & 50 & $24,106(14,111-34,101)$ & $482(282-682)$ \\
\hline $2388-2480$ & 0.71 & 0.07 & 92 & $15,340(8,980-21,701)$ & $167(98-236)$ \\
\hline $2480-2532$ & 0.64 & 0.34 & 52 & $74,509(43,615-105,403)$ & $1,438(842-2,035)$ \\
\hline $2532-2579$ & 0.30 & 0.02 & 47 & $4,383(2,566-6,200)$ & $94(55-132)$ \\
\hline $2579-2718$ & 0.28 & 0.00 & 139 & 0 & $\mathrm{~N} / \mathrm{A}$ \\
\hline $2718-2733$ & 0.28 & 0.28 & 15 & $61,361(35,918-86,803)$ & $4,037(2,363-5,711)$ \\
\hline $2733-3375$ & 0.00 & 0.00 & 641 & 0 & N/A \\
\hline
\end{tabular}

\footnotetext{
${ }^{1}$ Mean (minimum-maximum)

bgs $=$ Below ground surface

$\mathrm{ft}=$ Feet

$\mathrm{ft}^{2} / \mathrm{d}=$ Square feet per day

$\mathrm{ft} / \mathrm{d}=$ Feet per day

N/A = Not applicable
} 
The intervals in Table 3-6 with production (indicated by flow fraction) were determined from the flow logs, which did not span the entire length of the open borehole. However, the flow logs indicated that the entire production from the well originated from these intervals. This analysis provides a different view of the hydraulic conductivity of the formation than the average value produced by the analysis of the constant-rate test. That value represented an average $K$ for the LCA formation exposed in the ER-6-2 wellbore for testing. The flow logs indicated that there was no significant production from the UCCU below the LCA, so the length of UCCU formation exposed in the borehole was not included in the calculation. These interval values present a view of the variation of $K$ within the formation with respect to a natural scale for the variation.

\subsection{Comments on Well Test Design}

This section contains comments on the test design and implementation, and the effects that elements of the test data had on interpretation and analysis.

Recommendations for changes are provided. Future testing program schedules should be determined to the extent possible to provide improved information according to the recommendations provided below.

\subsubsection{Temperature Profile Logging}

As has been observed previously, substantial changes in the water column temperature profile (i.e., during pumping) result in an inaccurate record of the formation drawdown response as recorded with a PXD located a substantial distance above the production zone. This could be avoided by placing the PXD at the top of the production zone; however, this is often impractical. Appropriate high-range high-accuracy PXDs for this application would have to be purchased, which would be more expensive and prone to operational problems (e.g., leakage). Such placement would also interfere with other downhole data collection during pumping unless access tubing installed in the well were reconfigured for various parts of the testing procedures. Alternately, additional temperature logging to characterize the temperature profile change process could provide sufficient information to model the temperature change process so that the record could be accurately corrected. The level of information typically collected is not sufficient to characterize the process. At a minimum, a pre-test log, several logs during the temperature change process, and an equilibrium pumping temperature log should be collected. These could be collected during the development phase if the collection times were integrated into the schedule such that the temperature change process observed emulated the process during the constant-rate test.

The PXD temperature change record can be used as an approximate surrogate for the overall temperature change process, but this record does not necessarily provide an accurate basis for the correction of the drawdown record. The same temperature logging program as required for the direct correction would have to be conducted to calibrate the PXD temperature change record for this use. 


\subsubsection{Pre-Test and Post-Test Monitoring Records}

The processing of the water-level monitoring record to determine the drawdown response would be greatly improved with the collection of sufficiently long pre-test and recovery records to support accurate characterization of background trends. This is particularly relevant to wells (e.g., Well ER-6-2) in which the induced response is relatively small, such that the inaccuracy in the hydraulic conductivity estimate may be substantial. Also, the BE analysis was hampered by the short records collected and by the fact that these records were collected when the well was still equilibrating (both head and temperature) from previous pumping. In the case of this well, the temperature equilibration appears to have taken longer than the formation head equilibration. The pre-test record should at least equal the length of the test. The post-test record should continue until the well has fully recovered and temperature equilibrated. This generally should be determined by a comprehensive and detailed look at the monitoring records to evaluate the situation with respect to background trends.

\subsubsection{Background Monitoring Record}

A substantial improvement in the processing of the drawdown monitoring record to determine the actual drawdown response was afforded by the use of a contemporaneous record from a background well to remove non-specific noise in the testing drawdown record. Monitoring of a background well during testing should be considered for future testing programs to improve the test analysis quality. The background well should be selected with particular attention to the appropriate location, completion, and representativeness of the formation response for application to the wells to be tested. The record should start well before testing activities begin and extend past the completion of recovery monitoring for the test(s). This approach would improve the general quality of the test results.

\subsubsection{Pump Location}

To maximize access to the formation to be tested, the pump should be located as high in the well as possible, preferably within casing above the completion interval. Logging for flow and chemistry parameters can only be done below the pump because the logging tool must be run past the pump through an access line. However, for ER-6-2 the open formation extended from above the static water level requiring that the pump be located within the completion interval. The top of the pump was located about $89 \mathrm{ft}$ below the static water level. The maximum drawdown during testing of approximately $3.5 \mathrm{ft}$ would have allowed the pump to have been located up to $75 \mathrm{ft}$ higher in the well to meet operational requirements. This amount of drawdown is within the typical range for the LCA and may have been anticipated. The higher location would have provided access to more of the completion interval for flow logging.

Typically the flow logging calibration is adjusted to match the measured downhole maximum flow rate to the surface production measured rate (Section 3.5.1) 
according to information collected in the field. This is facilitated by well construction where flow to the pump is constrained within unperforated casing above the production interval. However, the construction of this well did not provide opportunity for such calibration measurements, and consequently, there is some additional uncertainty in the flow log interpretation. There is an inherent conflict for this well in providing this configuration because the static water level is within the formation of interest, and some of the saturated formation would have been made inaccessible by unperforated casing surrounding and below the pump.

\subsubsection{TFM Measurements}

The lack of TFM measurements (Section 2.3) in the completion interval made it difficult to evaluate flow in the wellbore under natural gradient (nonpumping) conditions, and especially flow associated with the reverse-from-normal temperature gradient in the lower part of the well. The ambient SFM logs were generally too noisy to support any detailed interpretation.

\subsection{Use of Well ER-6-2 for Monitoring}

The Well ER-6-2 completion is well connected to the formation and produces water from a substantial (428-ft) zone of the LCA. This well should provide suitable monitoring capability for water quality in this location as well as water-level trends in the LCA. There is no evidence that the formation in the well completion is not representative of the LCA in this area. However, as noted, the temperature profile in the lower part of the well is reversed from normal, a feature that should be evaluated for implications to the applicability of monitoring results.

\subsection{Summary}

This document presents the analysis of data from the FY 2004 testing program for Well ER-6-2. The water levels measured during the testing program served to define the formation pressure used for analysis of the constant-rate test but may not be indicative of a stable head. Monitoring by the USGS since 1994 shows that the head in the well has gradually increased and does not appear to have stabilized. The hydraulic test analysis provides an interpretation of the hydraulic characteristics for the LCA and an average value for $K$ over the interval of LCA exposed in the completion interval. Well-specific results include values of $K$ representative of the different flow intervals identified in the completion interval, which reflect the higher $K$ values of the fractured intervals. The flow logging indicated that some intervals within the LCA were nonproductive, that there were linear increases in production over some longer intervals, and that there were large step increases in production over some short intervals. 

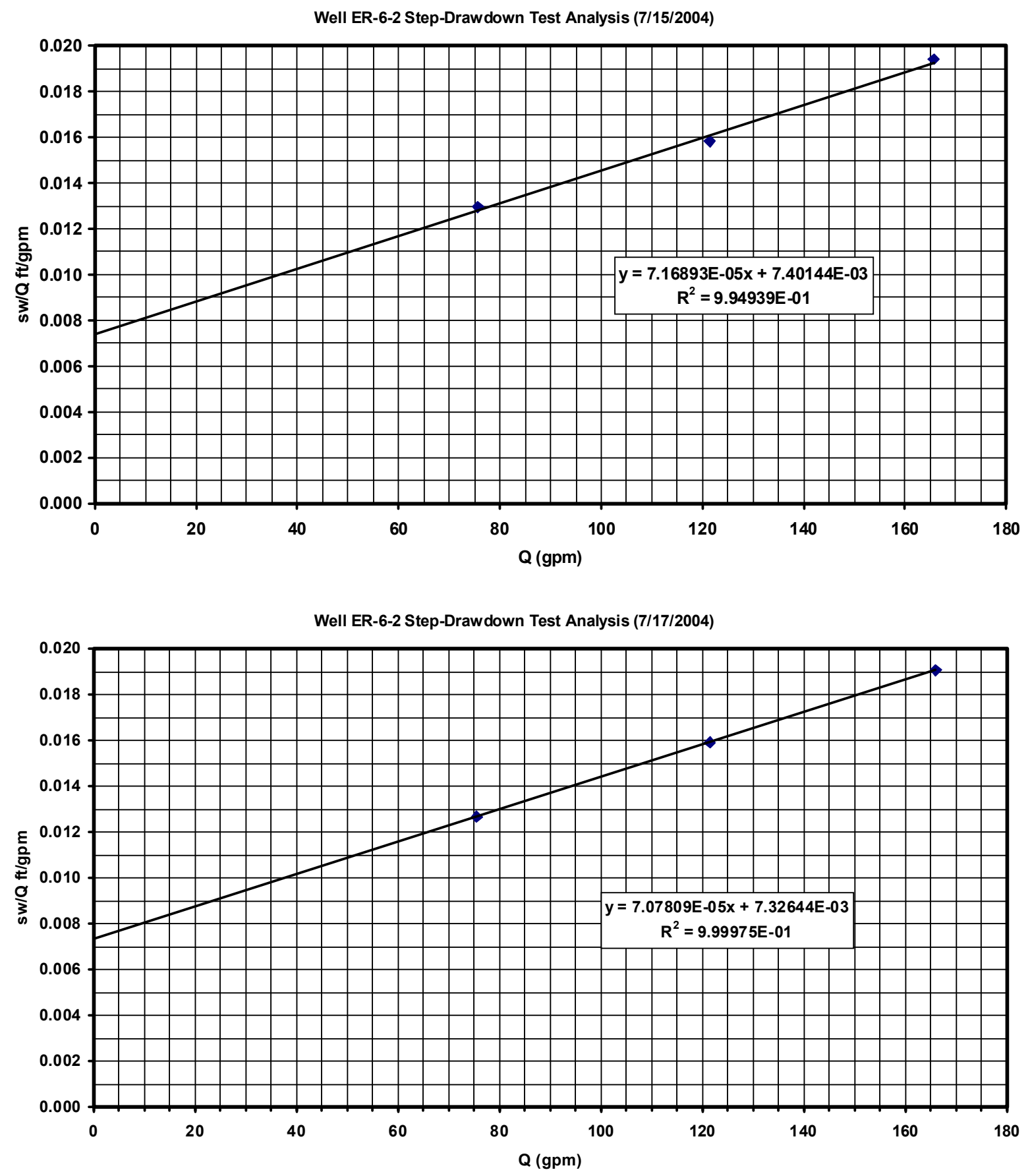

Figure 3-1

Step-Drawdown Test Data and Fits for Early-Time (above) and Late-Time (below) of the Well Development Period 
Overlay of Temperature Profiles

Temperature (Degrees Fahrenheit)

89

90

91

92

93

94

95

96

97

98

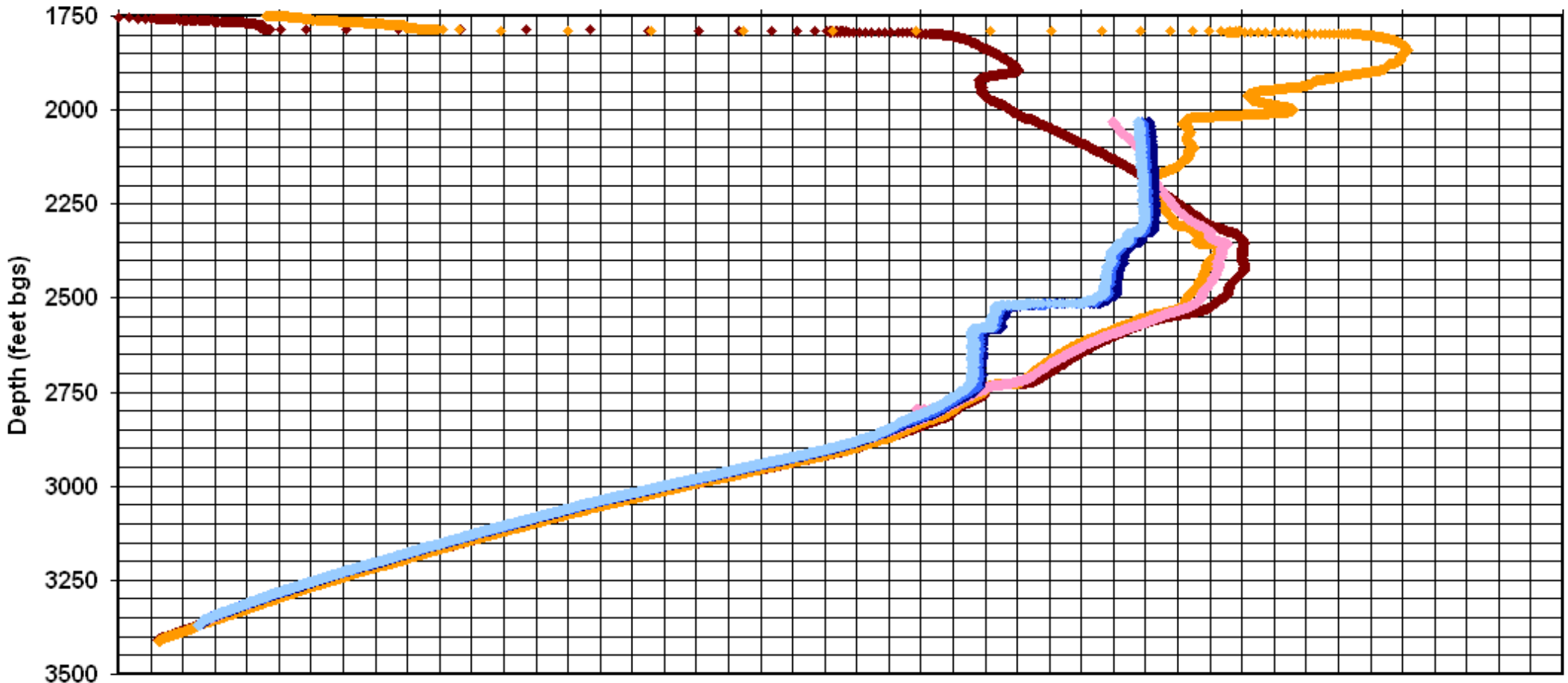

3500

\begin{tabular}{|c|c|c|c|}
\hline $\begin{array}{l}\text { - ER62T002,post-recovery } \\
\text { er62mov16a, } 120 \mathrm{gpm}\end{array}$ & $\begin{array}{l}\text { ER62T001, } 0 \mathrm{gpm} \\
\text { er62mov22a, } 165 \mathrm{gpm}\end{array}$ & er62mov04a, $0 \mathrm{gpm}$ & - er62mov10a, $75 \mathrm{gpm}$ \\
\hline
\end{tabular}

Figure 3-2

Overlay of Temperature Profiles for Well ER-6-2 


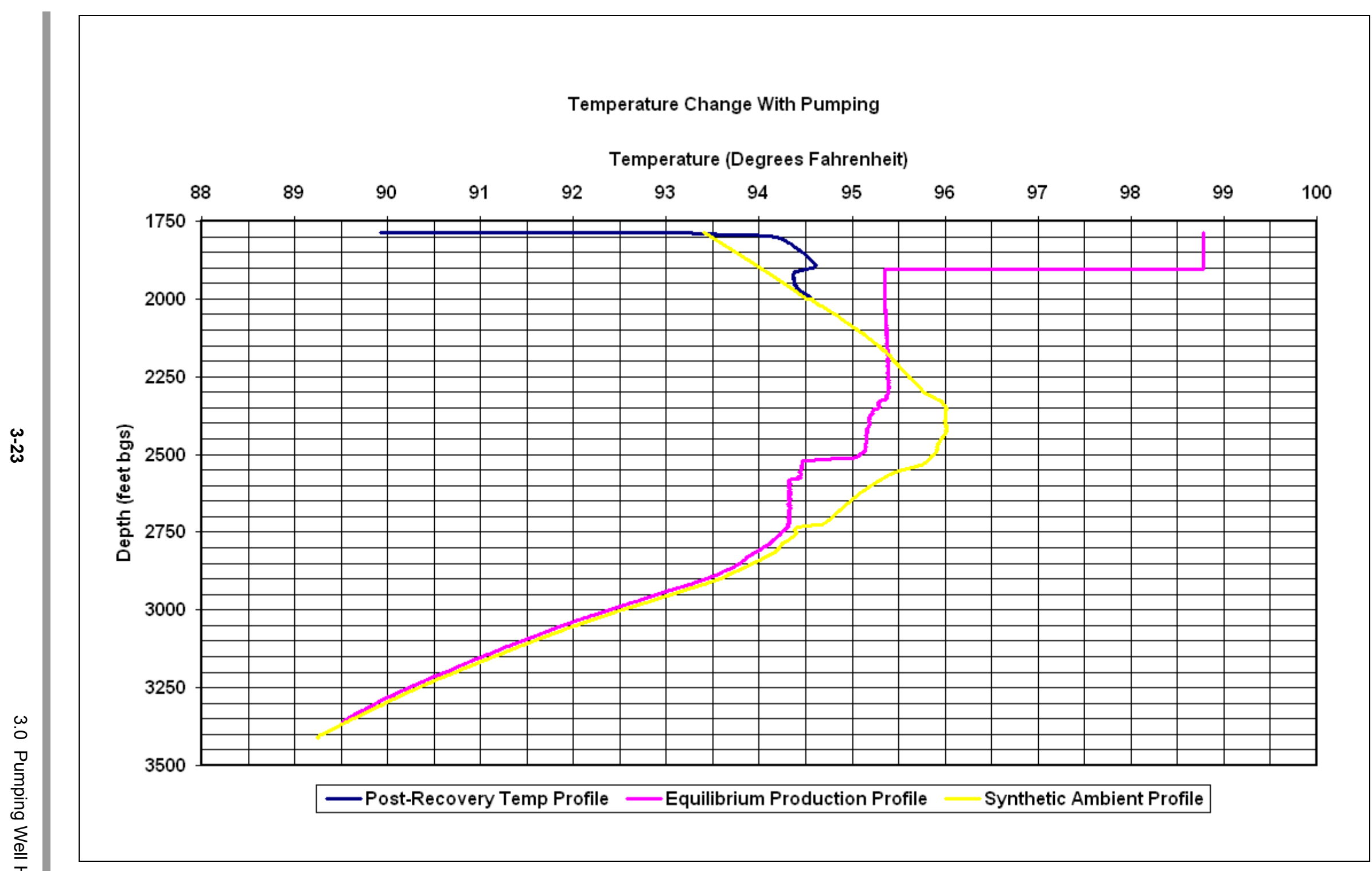

Figure 3-3

Synthetic Ambient and Pumping Temperature Profiles for Well ER-6-2 


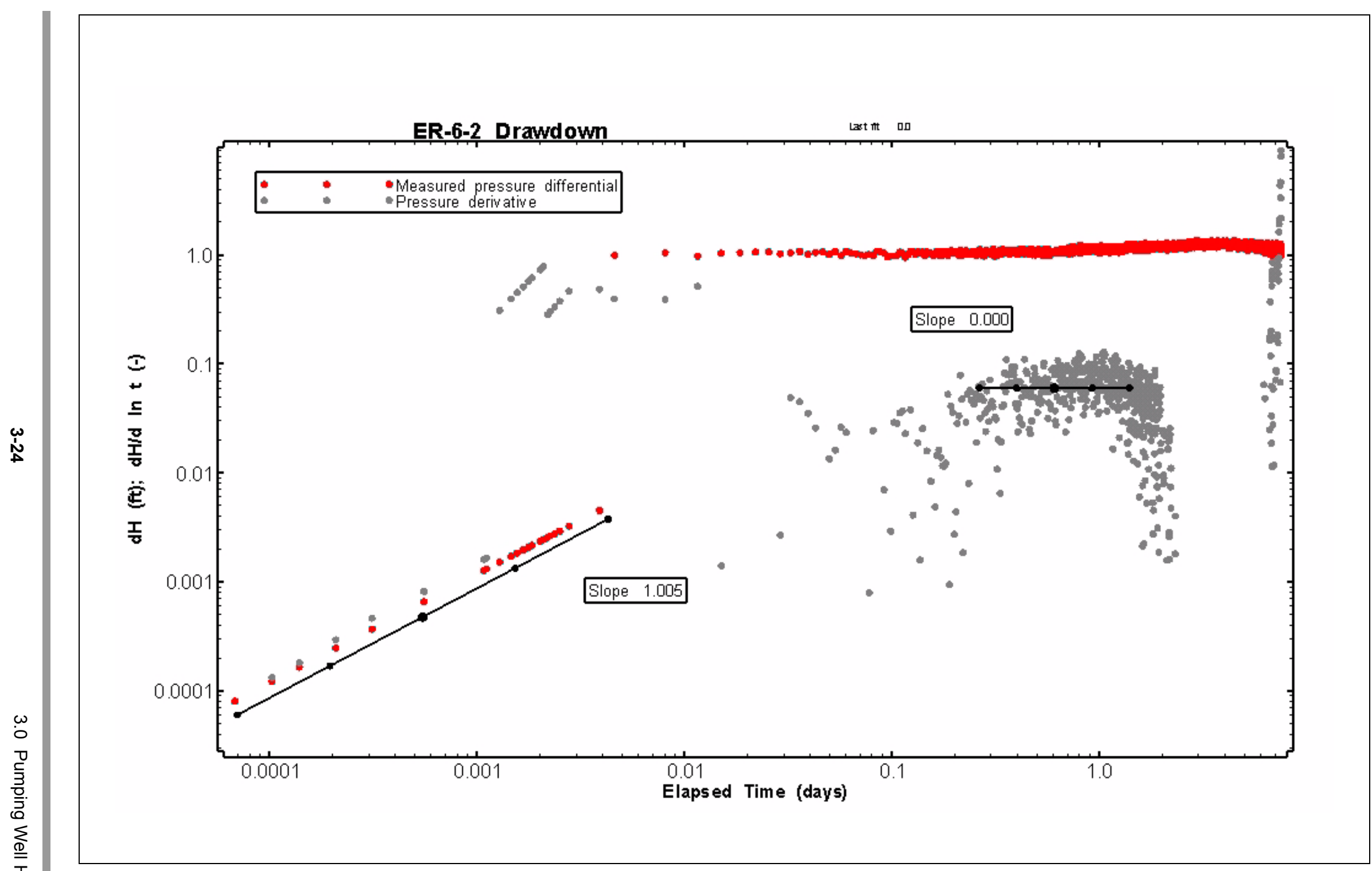

Figure 3-4

Log-Log Diagnostic Plot for the Complete ER-6-2 Drawdown Period

(10-day Constant-Rate Pump Test) 


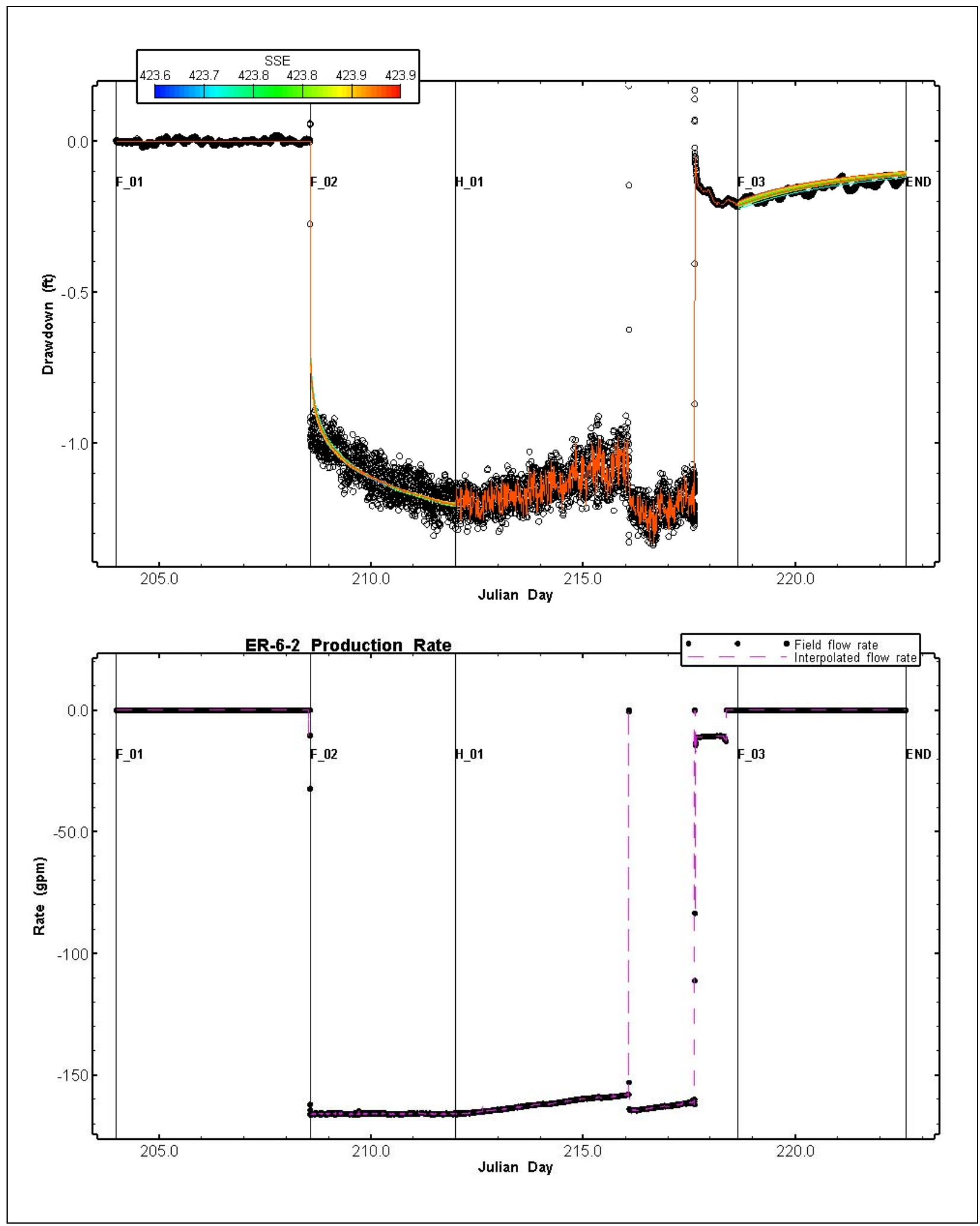

Figure 3-5

ER-6-2 Constant-Rate Pump Test Response with Best-Fit Simulated Responses (above) and Production Rate (below)

Sequence identification is presented in Section 3.4.3. 


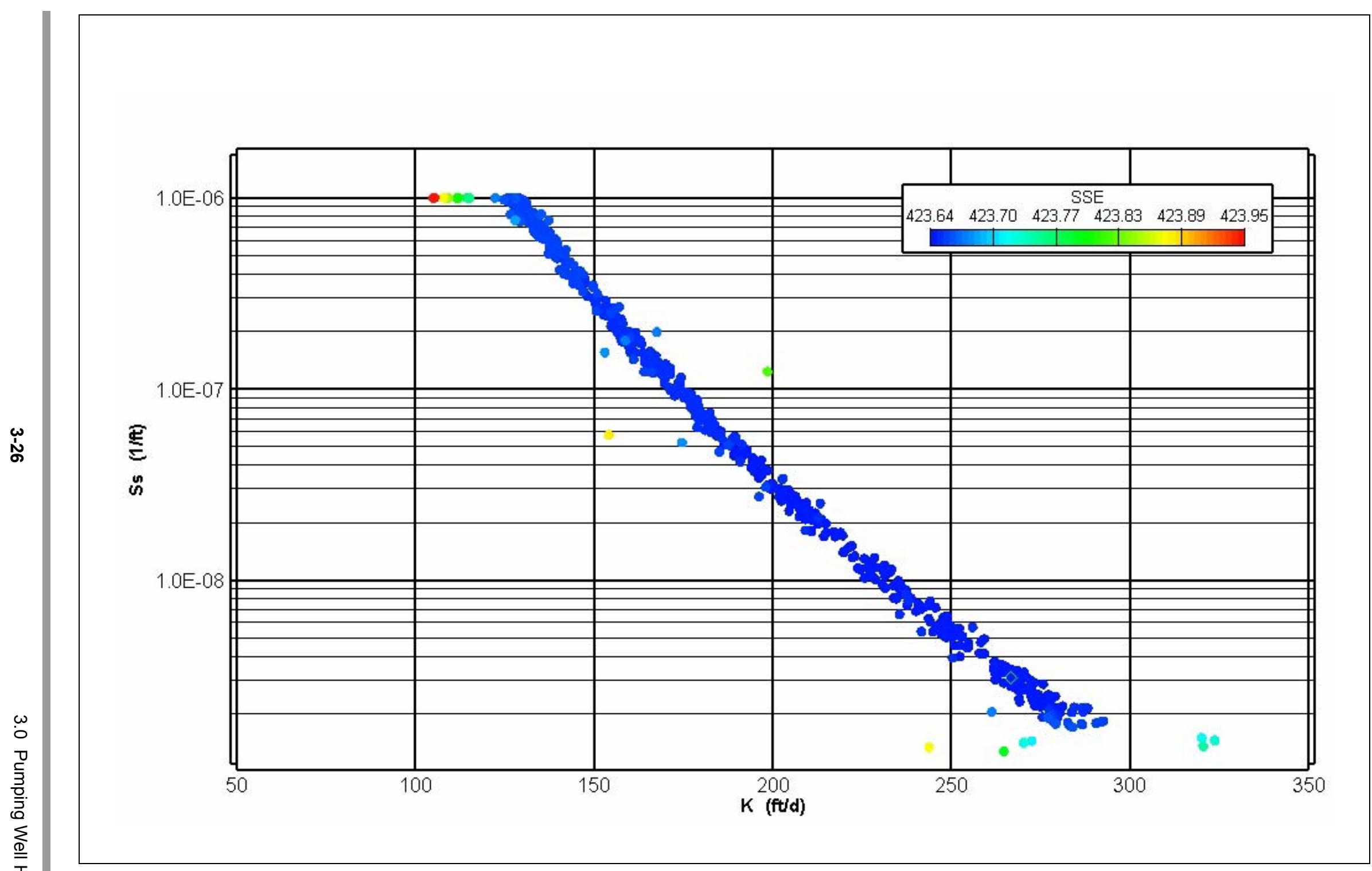

Figure 3-6

Best-Fit $K$ and $S$ Parameter Scatterplot 


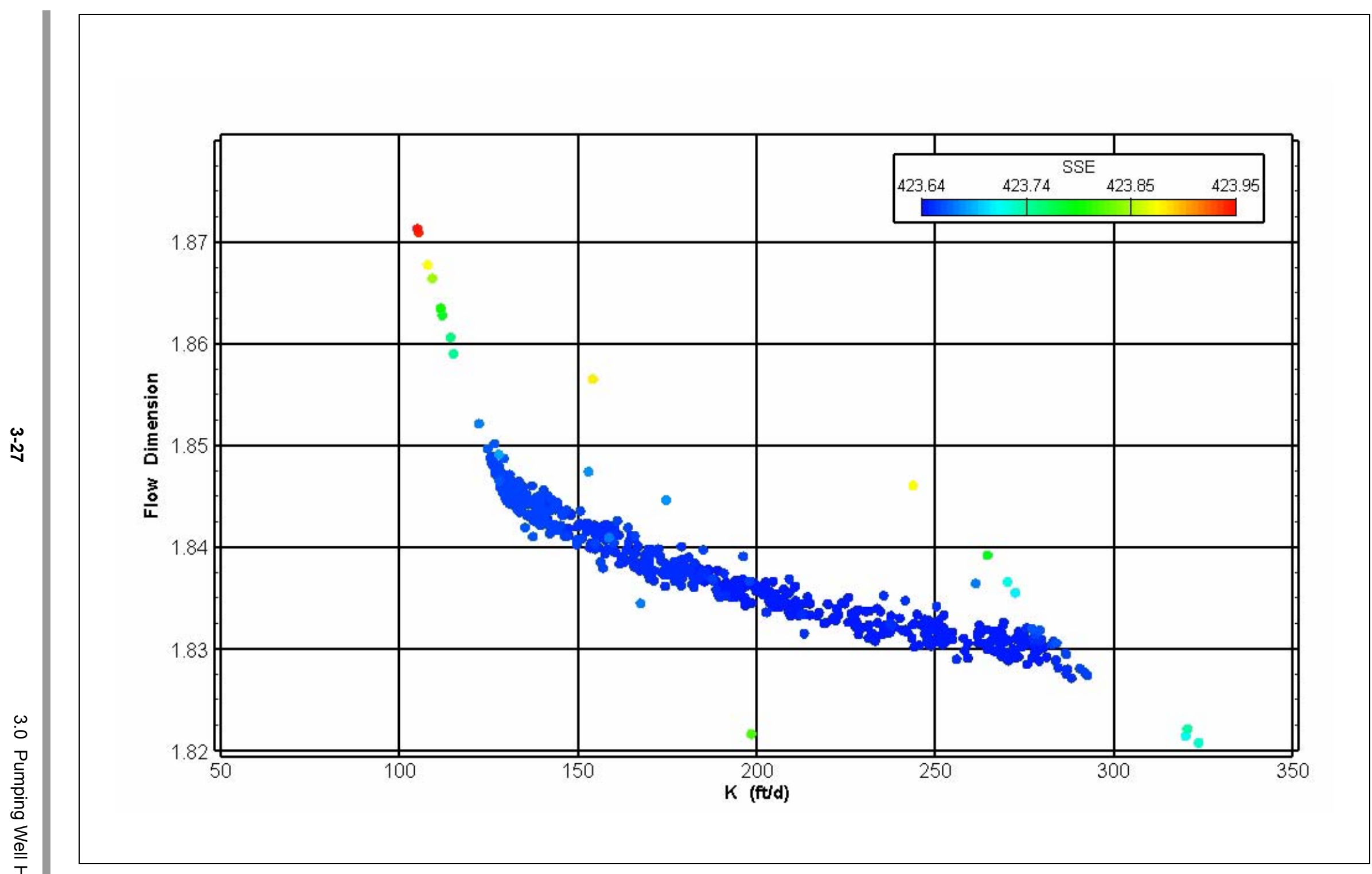

Figure 3-7

Best-Fit $K$ and $n$ Parameter Scatterplot 


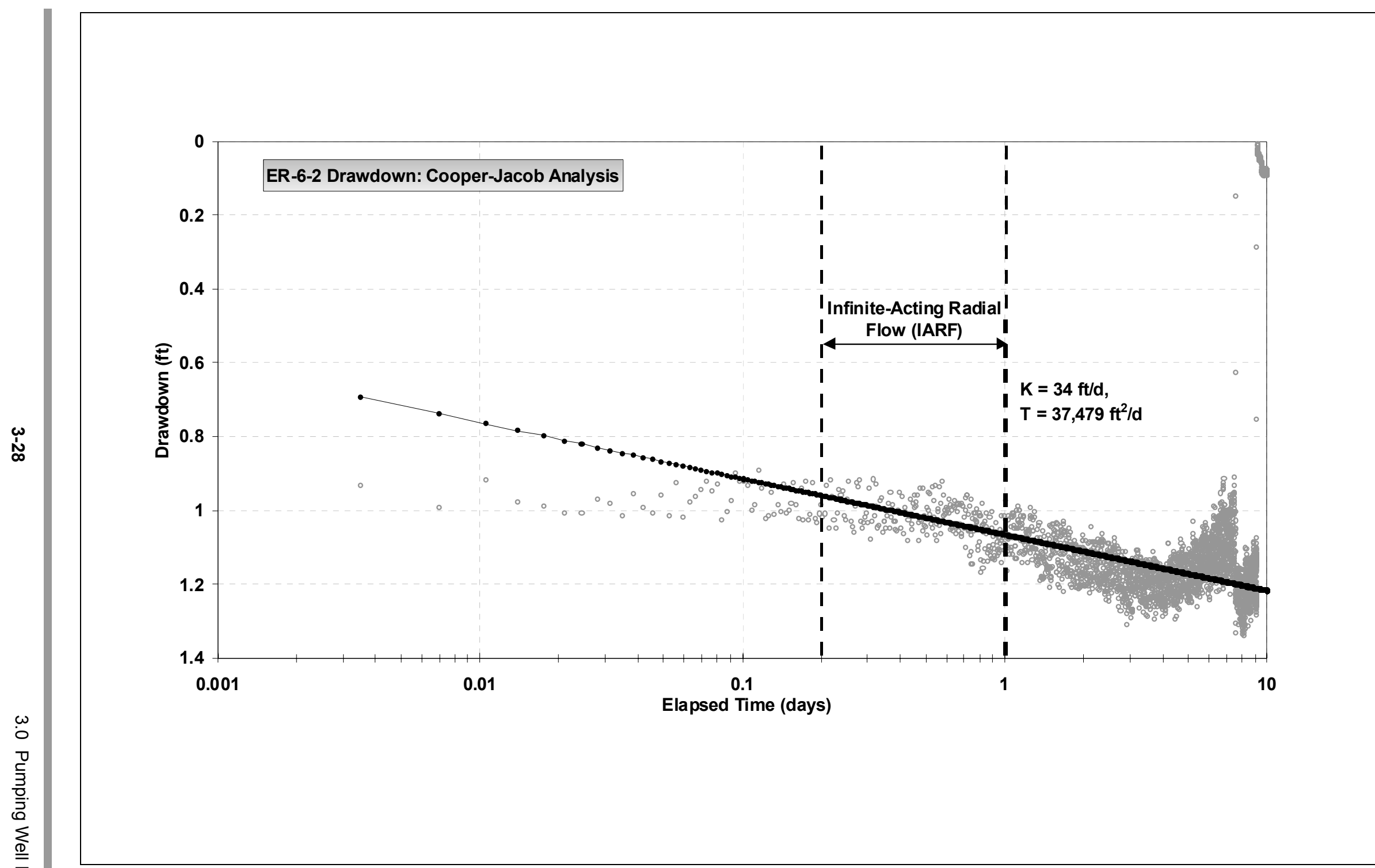

Figure 3-8

Cooper-Jacob Analysis of ER-6-2 Drawdown During the Observed Radial Flow Period 


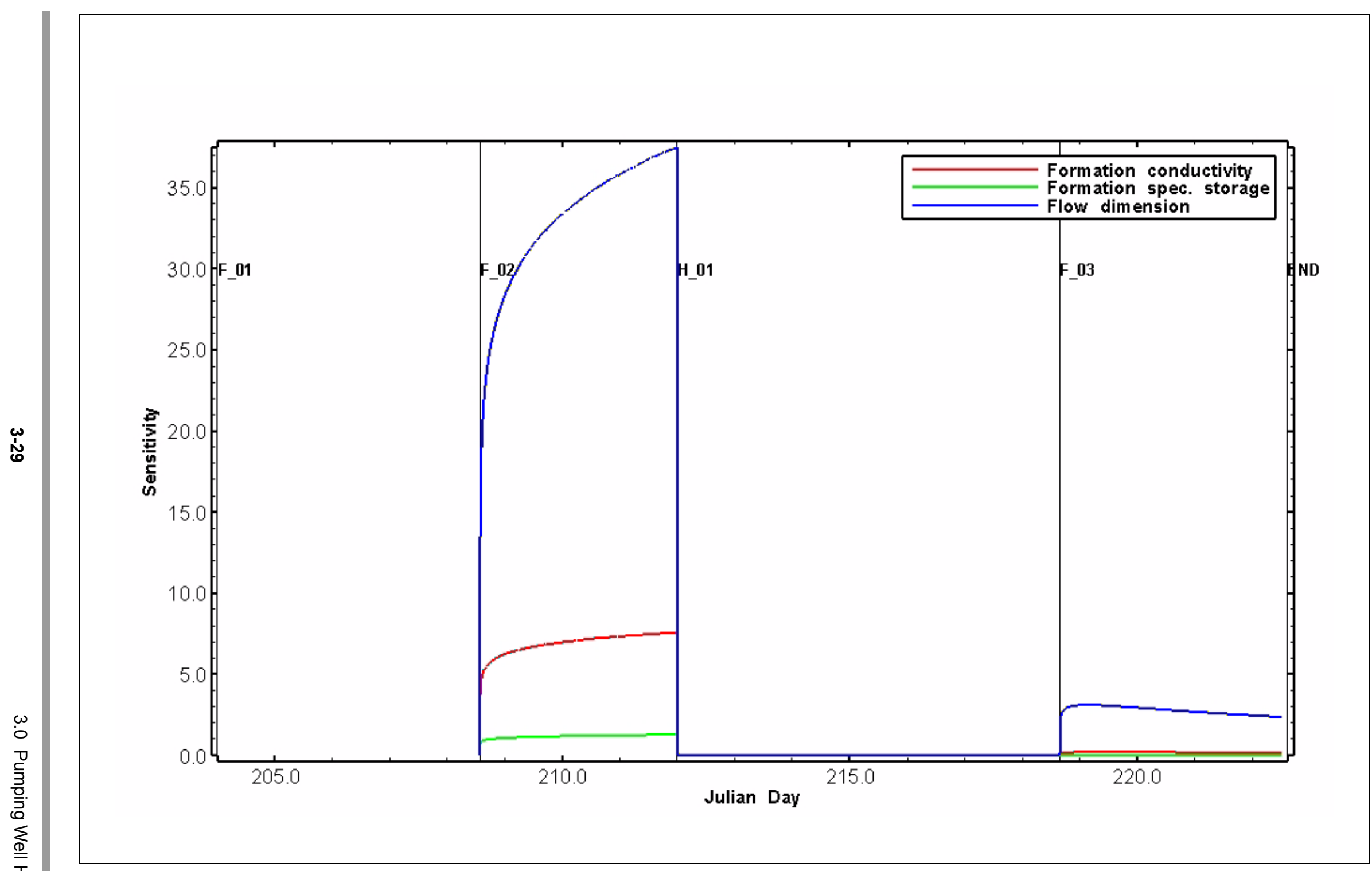

Figure 3-9

Fitting-Parameter Sensitivity Through the Complete ER-6-2 Pump-Test Record 
Overlay of $\mathbf{4 0} \mathrm{fpm}$ Up Flow Logs

Normalized Flow Rate

$-0.4$

$-0.1 \quad 0$

0.1

0.2

0.3

0.4

0.5

0.6

0.7

0.8

0.9

1

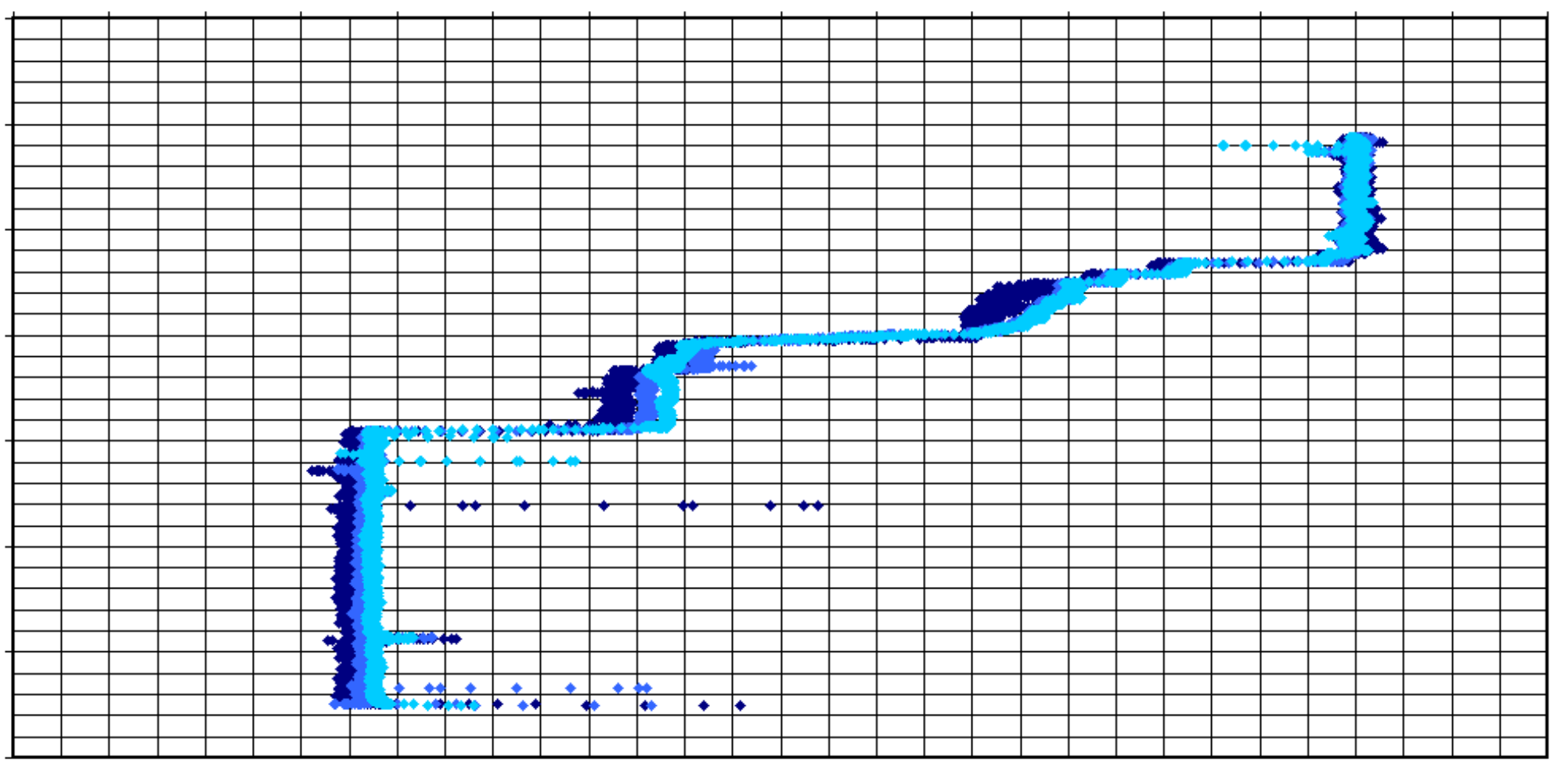

3500

- er62mov10a, $75 \mathrm{gpm}$ - er62mov16a, $120 \mathrm{gpm}$ - er62mov22a, $165 \mathrm{gpm}$ 
Overlay of Flow and Temperature Logs

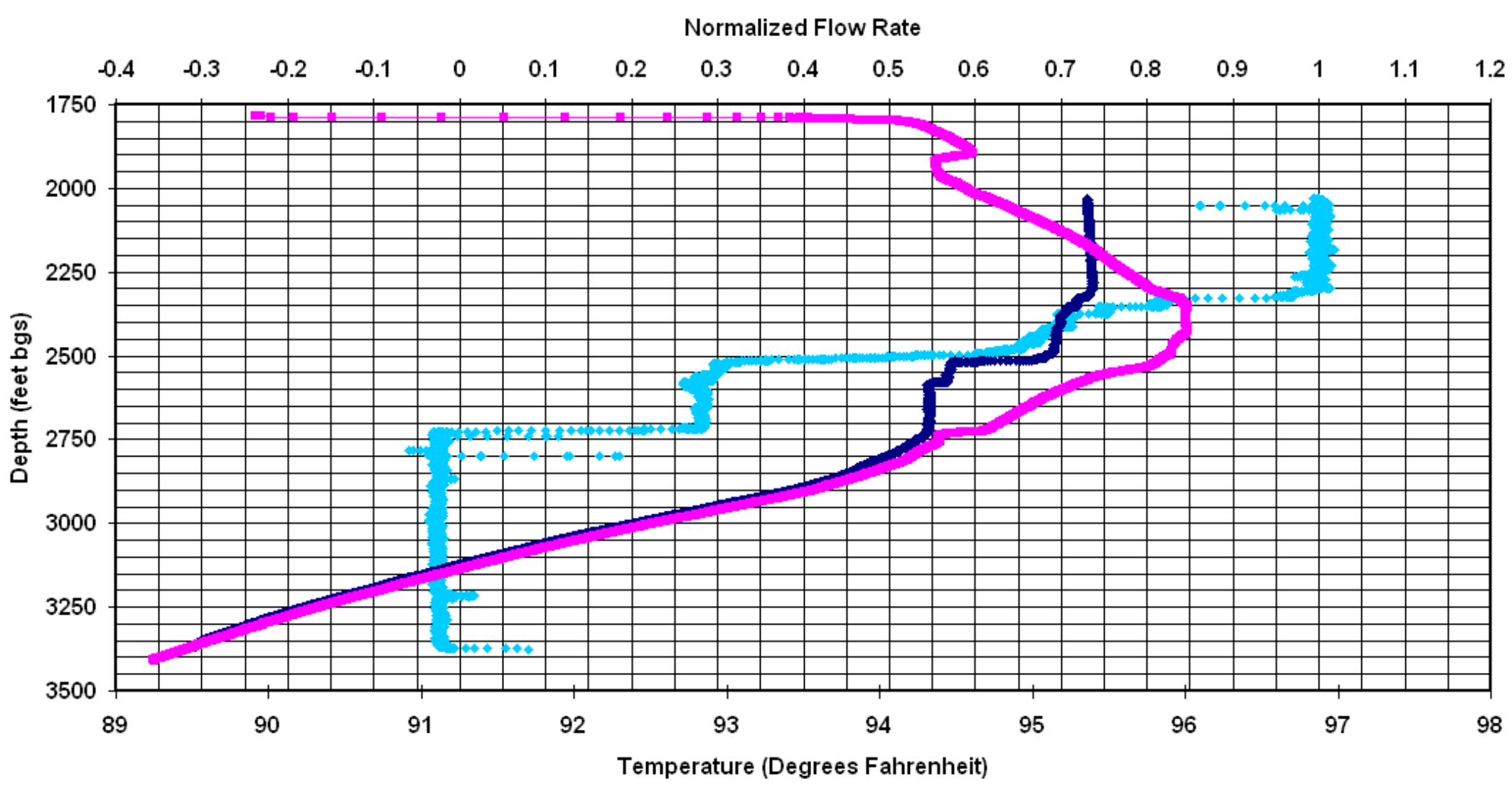

- er62mov22a Flow, $165 \mathrm{gpm} \rightarrow-$ er62mov22a Temperature, $165 \mathrm{gpm} \rightarrow-$ ER62T002 Temperature, post-recovery 
40 fpm Up Flow Log @ 165 gpm

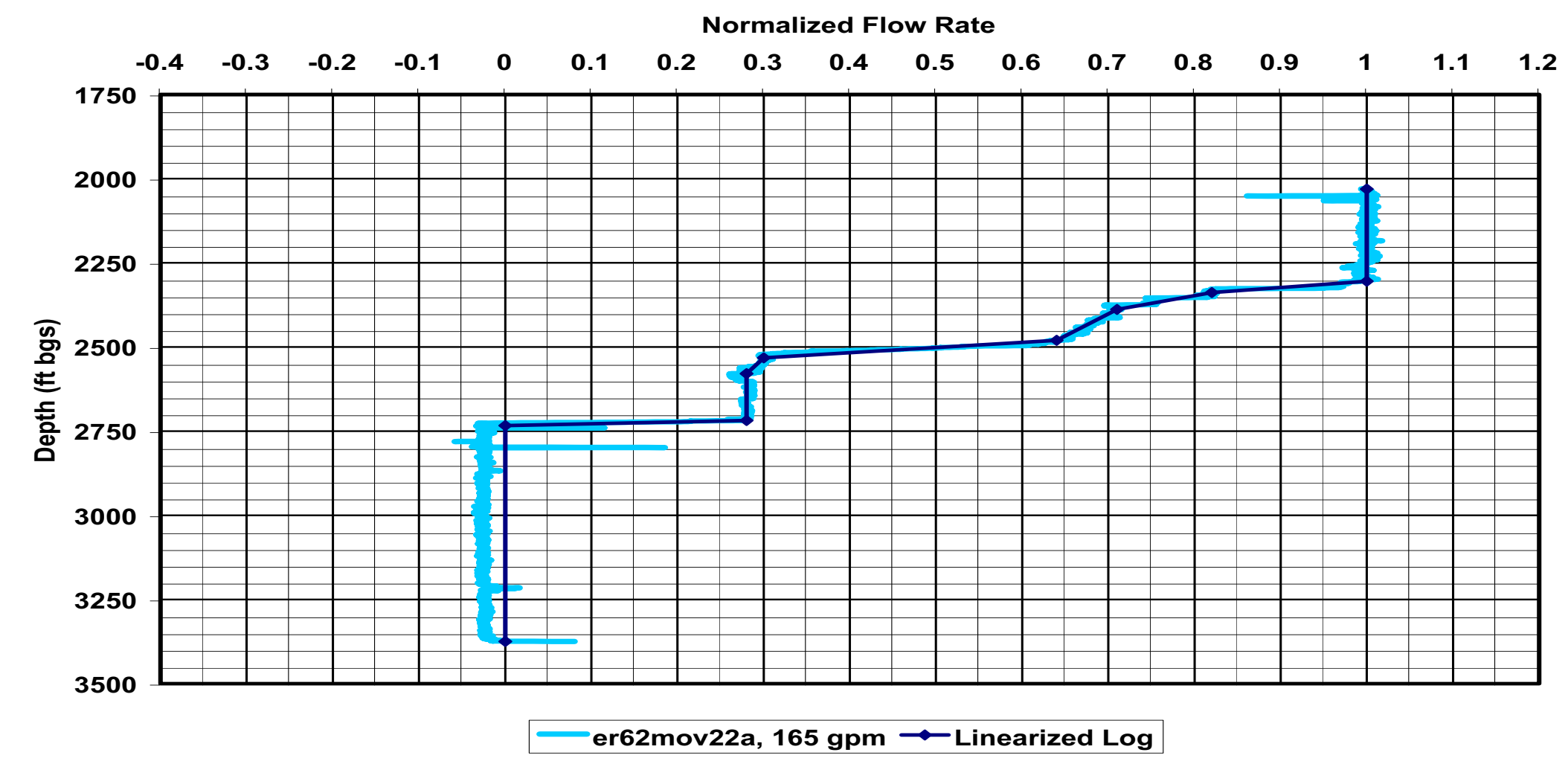

Figure 3-12

Linearized Pumping Flow Profile for Well ER-6-2 


\subsection{References}

ASME, see American Society of Mechanical Engineers.

American Society of Mechanical Engineers. 1990. Quality Assurance Requirements of Computer Software for Nuclear Facility Applications, ASME NQA-2a-1990 addenda, Part 2.7. New York, NY.

Barker, J.A. 1988. “A Generalized Radial Flow Model for Hydraulic Tests in Fractured Rock." In Water Resources Research, Vol. 24, No. 10. pp. 1796-1804

Belcher, W.R., P.E. Elliot, and A.L. Geldon. 2001. Hydraulic-Property Estimates for Use with a Transient Ground-Water Flow Model of the Death Valley Regional Ground-Water Flow System, Nevada and California, USGS Water-Resources Investigations Report 01-4210. Carson City, NV.

Bredehoeft, J.D. and S.S. Papadopulos. 1980. "A Method for Determining the Hydraulic Properties of Tight Formations." In Water Resources Research, 16(1), 233-238.

Cooper, H.H., Jr. and C.E. Jacob. 1946. "A Generalized Graphical Method for Evaluating Formation Constants and Summarizing Well-Field History." In Transaction American Geophysical Union, Vol. 27:526-534.

Washington, DC.

Cooper, H.H., Jr., J.D. Bredehoeft, and S.S. Papadopulos. 1967. "Response of a Finite-Diameter Well to an Instantaneous Charge of Water." In Water Resources Research, 3(1), 263-269.

CRC Press. 2000. CRC Handbook of Chemistry and Physics, 81st Edition. David R. Lide, Ph.D, Editor-in-Chief. Boca Raton, FL.

DOE/NV, see U.S. Department of Energy, Nevada Operations Office.

Garber, M.S., and W. Thordarson. 1962. Ground Water Test Well C, Nevada Test Site, Nye County, Nevada, USGS Report TEI-818.

Halford, K. 2005. Personal communication: spreadsheet for processing of water level monitoring data to remove effects of barometric pressure variation, earth tides, and water level trends, and instructions for use. 
Harr, M.E. 1987. Reliability-Based Design in Civil Engineering. Dover Press, Mineola, NY.

Horne, R.N. 1995. Modern Well Test Analysis. Palo Alto, CA: Petroway, Inc.

Javandel, I., and P.A. Witherspoon. 1969. "A Method of Analyzing Transient Fluid Flow in Multilayered Aquifers." In Water Resources Research, Vol. 5(4):856-869. Washington, DC: American Geophysical Union.

Kruseman, G.P. and N.A. de Ridder. 1990. "International Institute for Land Reclamation and Improvement." In Analysis and Evaluation of Pumping Test Data, Publication No. 47. The Netherlands: Wageningen.

Laczniak, R.J., J.C. Cole, D.A. Sawyer, and D.A. Trudeau. 1996. Summary of Hydrogeologic Controls on Ground-Water Flow at the Nevada Test Site, Nye County, Nevada. U.S. Geological Survey Water-Resources Investigations Report 96-4109.

Lohman, S. W. 1972. Ground-Water Hydraulics, U.S. Geological Survey, professional paper 708 .

Molz, F.J., R.H. Morin, A.E. Hess, J.G. Melville, and O. Guven. 1989. "The Impeller Meter for Measuring Aquifer Permeability Variations: Evaluation and Comparison with Other Tests." In Water Resources Research, Vol. 25(7):1677-1683. Washington, DC: American Geophysical Union.

Oberlander, P.L., and C.E. Russell. 2003. Depth-Specific Hydraulic Testing of Yucca Flat and Frenchman Flat Environmental Restoration Wells FY 2003. DRI Publication No. 45199, DOE/NV13609-28. Las Vegas, Nevada. September.

Pickens, J.F., G.E. Grisak, J.D. Avis, D.W Belanger, and M. Thury. 1987. "Analysis and Interpretation of Borehole Hydraulic Tests in Deep Boreholes: Principles, Model Development, and Applications." In Water Resource Research, Vol. 23(7), 1341-1375. Washington, DC: American Geophysical Union.

Press, W.H., S.A. Teukloksky, W.T. Vetterling and B.P. Flannery. 1992. Numerical Recipes in Fortran. Cambridge University Press, London, UK.

Roberts, R.M., R.L. Beauheim, and P.S. Domski. 1999. Hydraulic Testing of Salado Formation Evaporites at the Waste Isolation Pilot Plant Site: Final Report. Sandia Report SAND98-2537, July. Albuquerque, NM.

Rojstaczer, S. 1987. "The Local Effects of Groundwater Pumpage within a Fault-Influenced Groundwater Basin, Ash Meadows, Nye County, Nevada, U.S.A.” In Journal of Hydrology, Vol. 91, 319-337.

Amsterdam: Elsevier, BV.

SNJV, see Stoller-Navarro Joint Venture. 
Stoller-Navarro Joint Venture. 2004. Analysis of Well ER-7-1 Testing, Yucca Flat FY 2003 Testing Program, Nevada Test Site, Nevada, S-N/99205--021, Rev. 0, July. Las Vegas, NV.

Stoller-Navarro Joint Venture. 2005a. Written communication prepared for NNSA/NSO. Subject: "Data Report for the ER-6-1 Multiple-Well Aquifer Test, Yucca Flat FY 2004 Testing Program, Nevada Test Site, Nye County, Nevada." Las Vegas, NV.

Stoller-Navarro Joint Venture. 2005b. Written communication prepared for NNSA/NSO. Subject: "Yucca Flat Well ER-6-2 Data Report for Development and Hydraulic Testing," March. Las Vegas, NV.

Stoller-Navarro Joint Venture. 2005c. Analysis of Hydraulic Responses from the ER-6-1 Multiple-Well Aquifer Test, Yucca Flat FY 2004 Testing Program, Nevada Test Site, Nye County, Nevada, S-N/99205--051, June. Las Vegas, NV.

Theis, C.V. 1935. "The Relation Between the Lowering of the Piezometric Surface and the Rate and Duration of Discharge of a Well Using Groundwater Storage.” In Trans Amer. Geophys. Union, 2, pp. 519-524.

USGS, see United States Geological Survey.

U.S. Department of Energy, Nevada Operations Office. 1997a. Written communication prepared for NNSA/NSO. Subject: "Completion Report for Well ER-6-2," January. Las Vegas, NV.

U.S. Department of Energy, Nevada Operations Office. 1997b. Regional Groundwater Flow and Tritium Transport Modeling and Risk Assessment of the Underground Test Area, Nevada Test Site, Nevada, DOE/NV--477. Las Vegas, NV.

United States Geological Survey. 2005. Download of ER-6-2 water level monitoring graph from National Water Inventory System website at $\mathrm{http}: / /$ nevada.usgs.gov/doe\%5Fnv/sitepage_temp.cfm?site_id=36574011604 3501. June 8.

Walker D.D., and R.M. Roberts. 2003. "Flow Dimension Corresponding to Hydrogeologic Conditions." In Water Resources Res., 39(12), pp. 1349-1356.

Yeh, W.W-G. 1986. "Review of Parameter Identification Procedures in Groundwater Hydrology: The Inverse Problem." In Water Resources Research, Vol. 22, No. 2, pp. 95-108. 


\section{Distribution}

$\underline{\text { Copies }}$

Bill Wilborn

$2 \mathrm{HCs} / 2 \mathrm{CDs}$

U.S. Department of Energy

National Nuclear Security Administration

Nevada Site Office

Environmental Restoration Division

P.O. Box 98518, M/S 505

Las Vegas, NV 89193-8518

Shirley Doty

$1 \mathrm{HC} / 1 \mathrm{CD}$

U.S. Department of Energy

National Nuclear Security Administration

Nevada Site Office

Environmental Restoration Division

P.O. Box 98518, M/S 505

Las Vegas, NV 89193-8518

U.S. Department of Energy

$1 \mathrm{HC} / 1 \mathrm{CD}$

National Nuclear Security Administration

Nevada Site Office

Technical Library

P.O. Box 98518, M/S 505

Las Vegas, NV 89193-8518

U.S. Department of Energy

$1 \mathrm{CD}$

Office of Scientific and Technical Information

P.O. Box 62

Oak Ridge, TN 37831-0062

Southern Nevada Public Reading Facility

c/o Nuclear Testing Archive

P.O. Box 98521, M/S 400

Las Vegas, NV 89193-8521

Manager, Northern Nevada FFACO

$1 \mathrm{HC} / 1 \mathrm{CD}$

Public Reading Facility

c/o Nevada State Library \& Archives

100 N. Stewart Street

Carson City, NV 89193-8521

P.K. Ortego

$2 \mathrm{HCs} / 2 \mathrm{CDs}$

Bechtel Nevada

P.O. Box $98521 \mathrm{MS} / \mathrm{NLV} 82$

Las Vegas, NV 89193

$1 \mathrm{HC} / 1 \mathrm{CD}$ 
S.I. Drellack

$1 \mathrm{HC} / 1 \mathrm{CD}$

Bechtel Nevada

P.O. Box 98521 MS/NLV 82

Las Vegas, NV 89193

B.K. Thompson

$1 \mathrm{HC} / 1 \mathrm{CD}$

U.S. Geological Survey

160 N. Stephanie St.

Henderson, NV 89074

R.P. Graves

$1 \mathrm{HC} / 1 \mathrm{CD}$

U.S. Geological Survey

160 N. Stephanie St.

Henderson, NV 89074

C.E. Russell

$1 \mathrm{HC} / 1 \mathrm{CD}$

Desert Research Institute

755 E. Flamingo Road

Las Vegas, NV 89132-0040

N.M. Becker

$1 \mathrm{HC} / 1 \mathrm{CD}$

Los Alamos National Laboratory

Hydrology, Geochemistry, and Geology Group, EES-6

Earth and Environmental Sciences Division

SM-30, Bikini Atoll Rd., MS F665

Los Alamos, NM 87545

P.W. Reimus

$1 \mathrm{HC} / 1 \mathrm{CD}$

Los Alamos National Laboratory

P.O. Box 1663, M/S J534

Los Alamos, NM 87545

G.A. Pawloski

$1 \mathrm{HC} / 1 \mathrm{CD}$

Lawrence Livermore National Laboratory

7000 East Avenue, L-221

Livermore, CA 94551-0808

T.P. Rose

$1 \mathrm{HC} / 1 \mathrm{CD}$

Lawrence Livermore National Laboratory

7000 East Avenue, L-231

Livermore, CA 94551-0808

R.M. Maxwell

$1 \mathrm{HC} / 1 \mathrm{CD}$

Lawrence Livermore National Laboratory

7000 East Avenue

Livermore, CA 94551 
John McCord

$1 \mathrm{HC} / 1 \mathrm{CD}$

Stoller-Navarro Joint Venture

7710 W. Cheyenne, Bldg. 3

Las Vegas, NV 89129

Jeffrey Wurtz

$1 \mathrm{HC} / 1 \mathrm{CD}$

Stoller-Navarro Joint Venture

7710 W. Cheyenne, Bldg. 3

Las Vegas, NV 89129

Greg Ruskauff

$1 \mathrm{HC} / 1 \mathrm{CD}$

Stoller-Navarro Joint Venture

7710 W. Cheyenne, Bldg. 3

Las Vegas, NV 89129

Eric Bhark

$1 \mathrm{HC} / 1 \mathrm{CD}$

Stoller-Navarro Joint Venture

7710 W. Cheyenne, Bldg. 3

Las Vegas, NV 89129

Bill Fryer

$1 \mathrm{HC} / 1 \mathrm{CD}$

Stoller-Navarro Joint Venture

7710 W. Cheyenne, Bldg. 3

Las Vegas, NV 89129

Central Files

$1 \mathrm{HC} / 1 \mathrm{CD}$

Stoller-Navarro Joint Venture

7710 W. Cheyenne, Bldg. 3

Las Vegas, NV 89129

Public Reading Facility Coordinator

$1 \mathrm{HC} / 1 \mathrm{CD}$

Stoller-Navarro Joint Venture

7710 W. Cheyenne, Bldg. 3

Las Vegas, NV 89129 